\title{
THE QUALITATIVE DEGRADATION OF AGRICULTURAL AND ITS IMPACT ON PRODUCTIVITY CHANGES AND FOOD SECURITY IN EGYPT
}

\author{
ASMAA SALEH ABD EL MONEM
}

Agricultural Economics Research Institute, ARC, DoKKi, Giza

(Manuscript received 15 February 2017)

\begin{abstract}
$\mathrm{T}$ he research aims to identify qualitative deterioration that has occurred on the competence of productivity for the different administrative districts to assist in the preparation of plans and programs for the improvement and maintenance of agricultural soil, which helps to guide the farmer to achieve the best cropping pattern. This study was reached to the number of districts increase from the 164 districts during the first period for the classification (1996/2000) to about 209 districts during the second period for the classification (2006/2010), while planted area of field crops Increased during the first period from about 7.8 million fed to 8.3 million fed during the second period. The qualitative deterioration converted to the deterioration during both study estimated at about 67,5 thousand fed. By studying the impact of qualitative deterioration on the net return of the main agricultural crops for some alternative course during the period (2010/2015) the highest value for the course (clover and rice) at about 941 thousand L.E , the highest value of the loss of jobs for a number of human labor about 6 million workers to course (winter onions and rice), By evaluating the impact of qualitative deterioration on food security for the most important agricultural crops, the results showed that the highest of amount loss in the local production, available for consumption, net food and the in the wheat crop the losses as a result of qualitative deterioration of about 594 thousand tons, 1.14 million tons, 776.3 thousand tons, while the self-sufficiency of wheat was about $51.8 \%$. The study also showed that the volume of investments directed to overcome the qualitative deterioration of agricultural land increased from about 47.8 million L.E during the first year of the investment plan to about 452.3 million L.E during sixth year of the plan. The carried out of the investment plan reached in the first year of the plan about 31.2 million L.E, and about 413.9 million L.E during sixth year of the plan, the total area which was carried out improvement about 37 million fed. In the light of the obtained result, the study recommends the importance of put an integrated plan for expansion in different improvement programs for all governorates of the Republic and encourage and increase investments directed to projects for improve the land in the country.
\end{abstract}




\section{التدهور النوعى للأراضى الزراعية وأثره على الأى

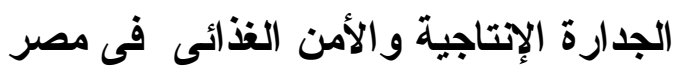

\section{أسماء صالح عبد المنعم}

\section{معهُ بحوث الافتصاد الزراعي - مركز البحوث الزراعية - دقى - جيزه}

نو اجه عملية التتمية فى القطاع الزر اعي المصري العديد من المعوقات والتـي

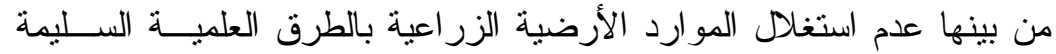

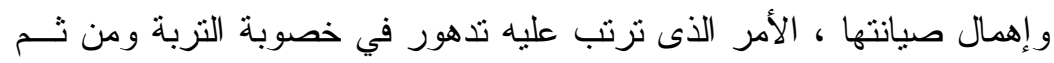

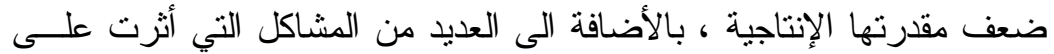

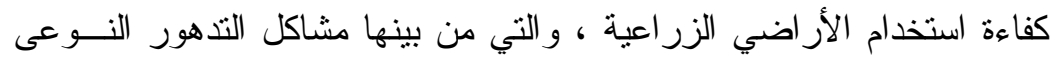
الذى يؤدى الى ضعف جدارتها الإنتاجية ، و التكثيف الزر اعي لوحدة المساحة

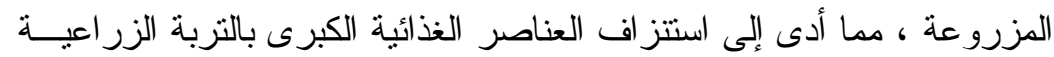

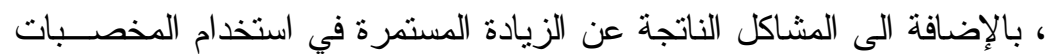
الكيميائية ، الأمر الذى يؤدى إلى العديد من المخاطر و التي تؤثر على الصحة

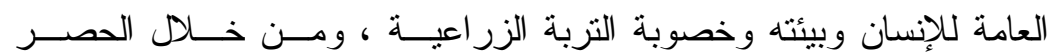

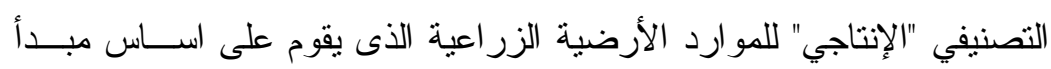

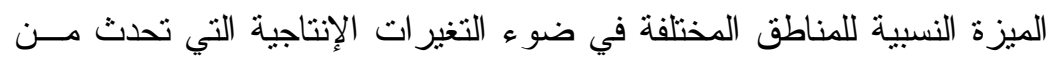

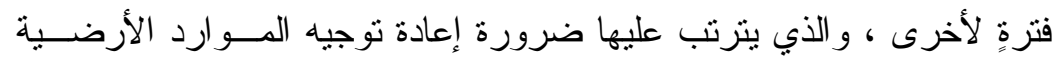

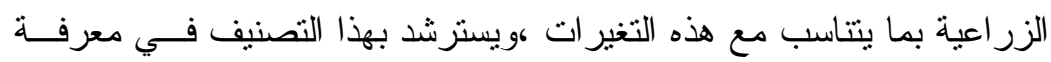

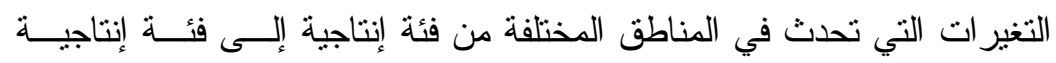

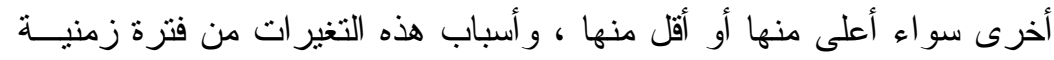

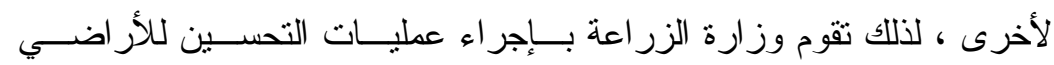

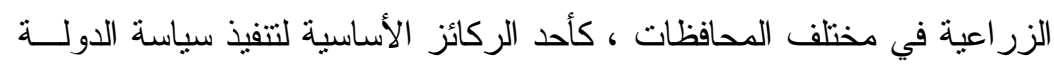

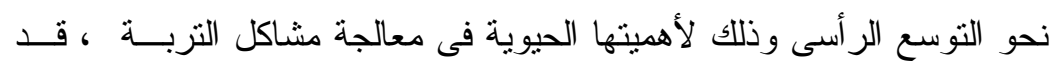

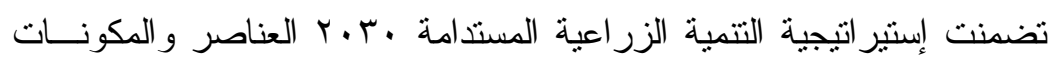

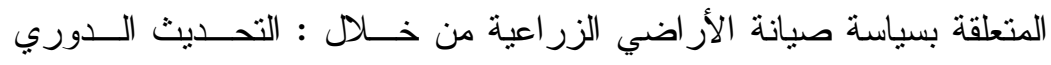

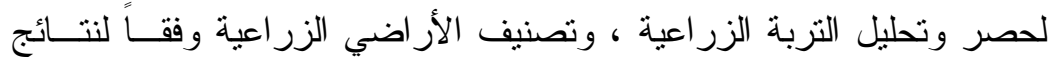

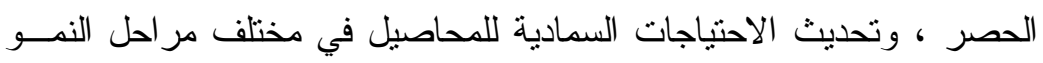

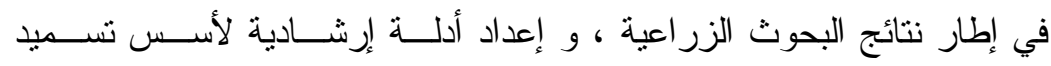
المحاصيل حسب مناطق زر اعتها ووضع نظام لتوزيع الأسمدة وتخطيط وتتفيذ

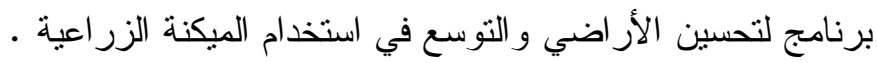




\section{مشكلة البحث}

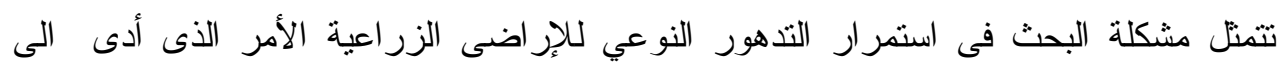

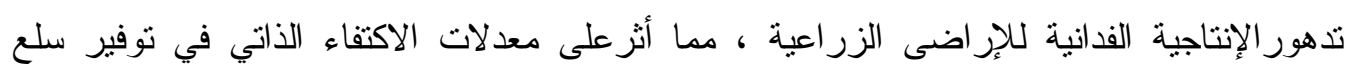

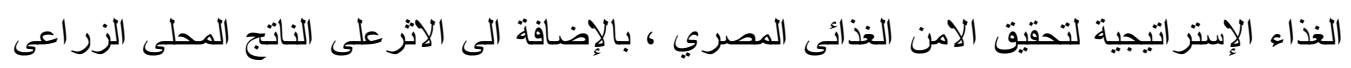

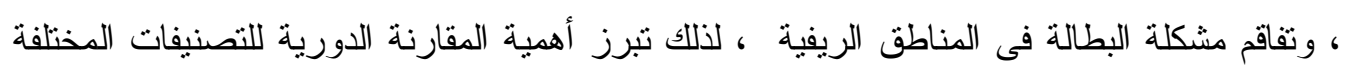

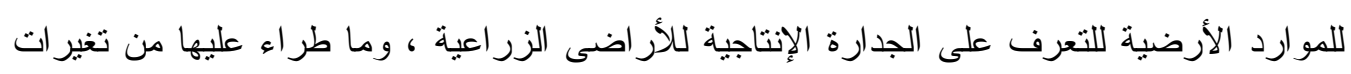

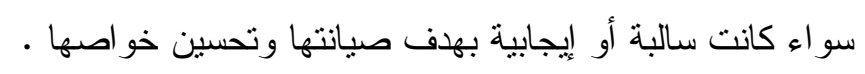

\section{هــدف البحث}

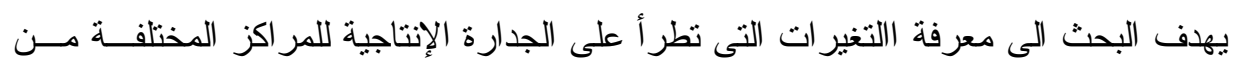

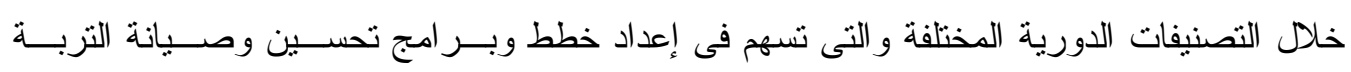

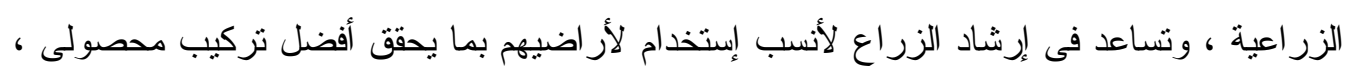
وسوف يتم تحقيق الهدف الرئيسي للبحث من خلال الوسائل النالية :

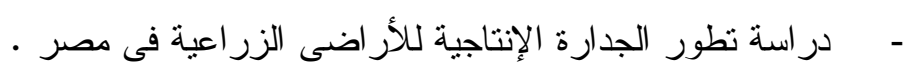

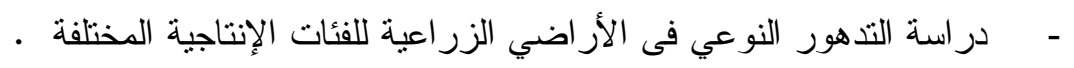

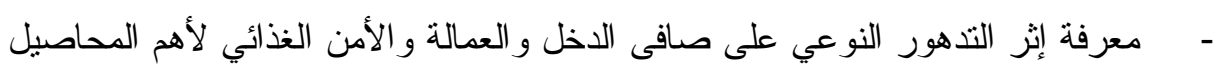
الزر اعية .

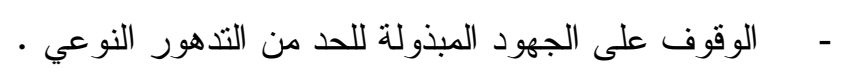

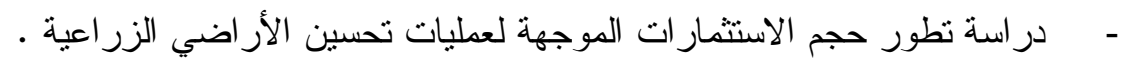
- - التعرف على أثر التحسين على الإر اضى الزر اعية لأهم محافظات الجمهورية ل

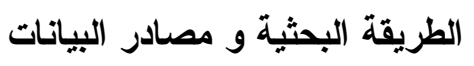

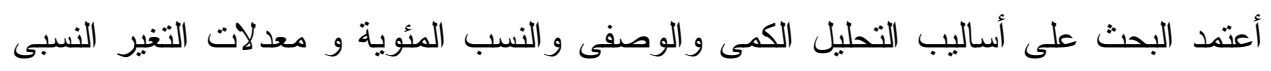

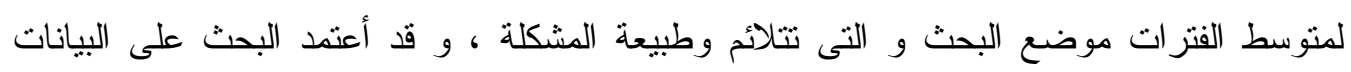

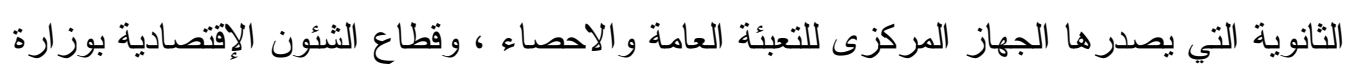

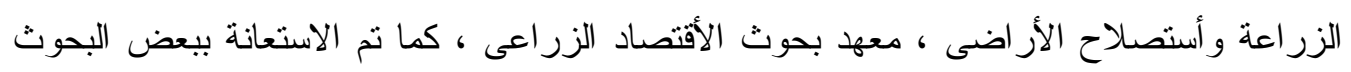

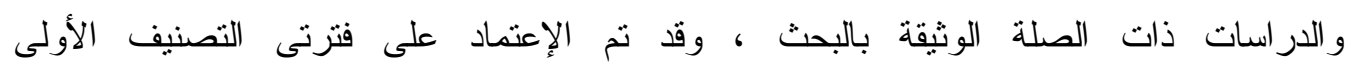

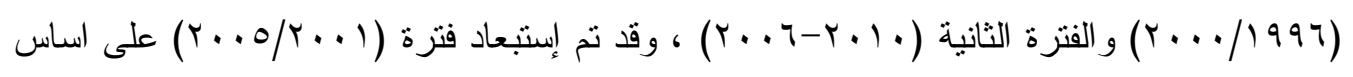

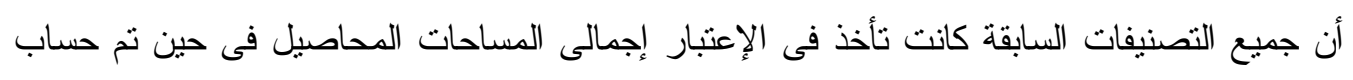

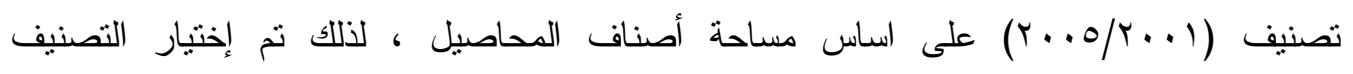
الإخيروقبل الإخيرلتجنب الإخطاء فى المقارنات ، لمعرفة مدى التغير الذى حدث للرتب الإنى الإنتاجية

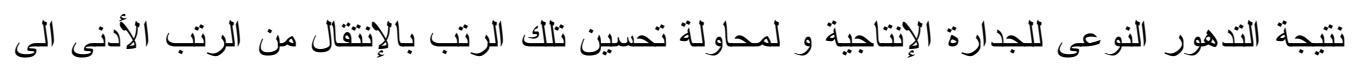

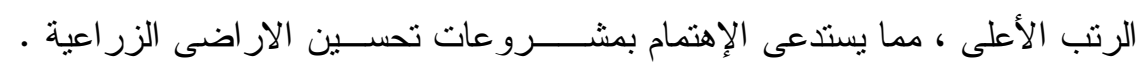




\section{مناقشة النتائج}

أولاً : تطور الجدارة الإنتاجية للأراضى الزراعية :

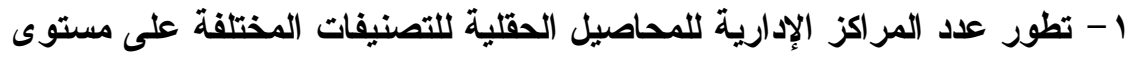

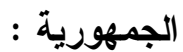

يوضح الجدول رقم (1) تطور عدد مراكز الرقعة الزراعية للمحاصيل الحقلية خلال الفترة

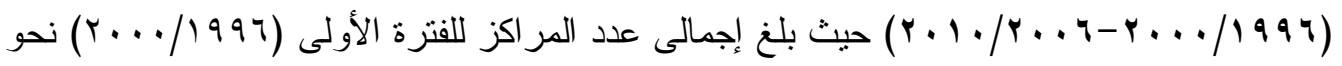

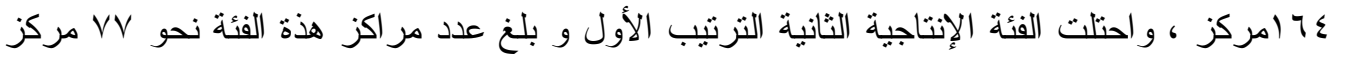

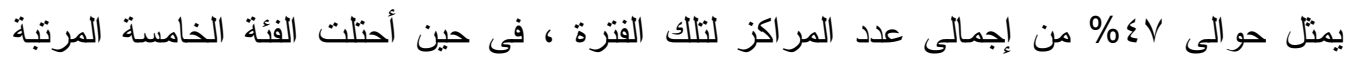
الأخيرة حيث بلغ عدد مر اكز هذة الفئة نحو r مر اكز تمنل حوالى بـ من من إجمالى عدد المر اكز

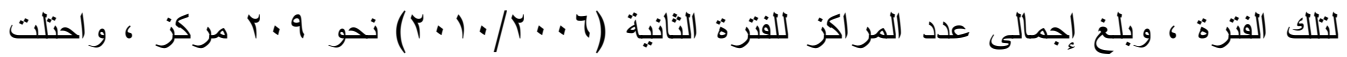

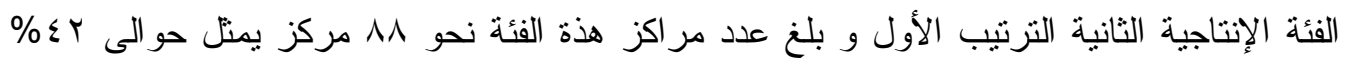

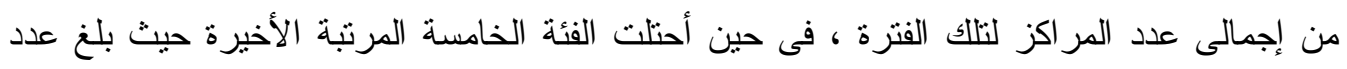

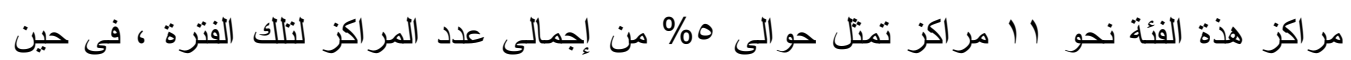

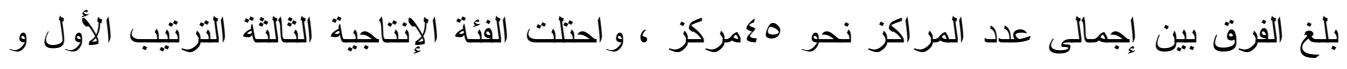

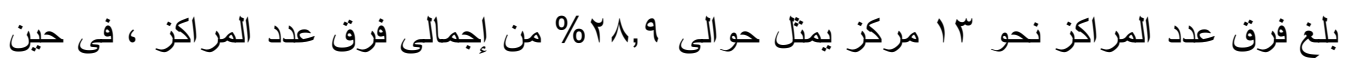

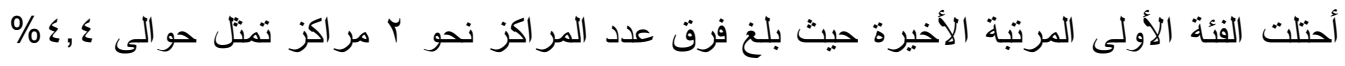

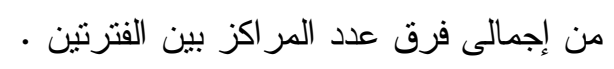

جدول (1) عدد مر اكز الرقعة الزر اعية للمحاصيل الحقلية

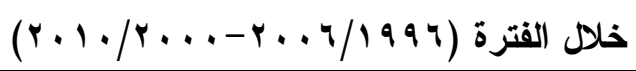

\begin{tabular}{|c|c|c|c|c|c|c|}
\hline \multicolumn{2}{|c|}{ الفرق بين الفترتين } & \multicolumn{2}{|c|}{ 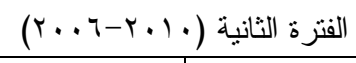 } & \multicolumn{2}{|c|}{ 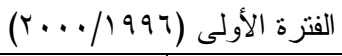 } & \multirow{2}{*}{ الإنتاجية } \\
\hline \% من الإجمالى & عد المد اكز & \% من الإجمالى & عدد المر اكز & \% الإجمالى من & عدد المر اكز & \\
\hline$\varepsilon, \varepsilon$ & r & rq & 7. & ro & 01 & 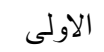 \\
\hline$r \varepsilon, \varepsilon$ & 11 & $\varepsilon r$ & $\wedge$ & $\sum V$ & VV & الثانية \\
\hline$r \wedge, q$ & ir & iv & ro & ir & rt & 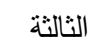 \\
\hline$T \varepsilon, \varepsilon$ & 11 & V & 10 & $r$ & $\varepsilon$ & الر ابعة \\
\hline $\mid \gamma, \Lambda$ & $\wedge$ & 0 & 11 & $r$ & $r$ & الخامسة \\
\hline $1 \ldots$ & $\leqslant 0$ & $1 \ldots$ & $r . q$ & $1 \ldots$ & $17 \varepsilon$ & الجملة \\
\hline
\end{tabular}

المصدر : جمعت وحسبت من وزارة الزراعة والاسنصلاح الأراضى - مركز البحوث الزراعية - معهد بحوث

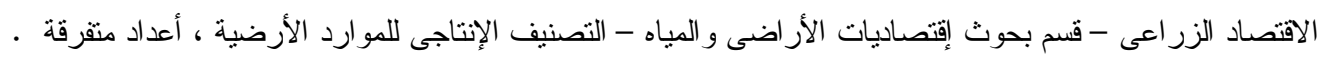

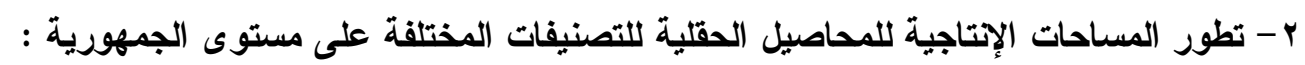
يوضح الجدول رقم (r) تطور مساحات الرقعة الزراعية للمحاصيل الحقلية خلال الفترة

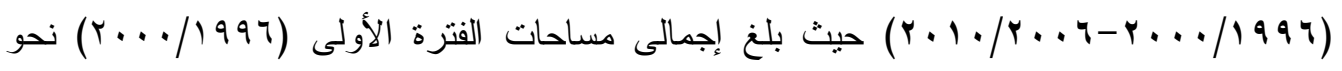

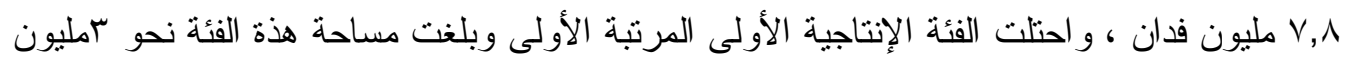

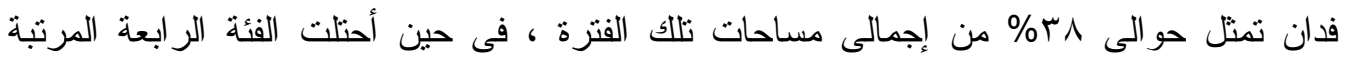


الأخيرة وبلغت مساحة هذة الفئة نحو 0 ابالف فدان تمثل حوالى r\% من إجمالى مساحات تلك

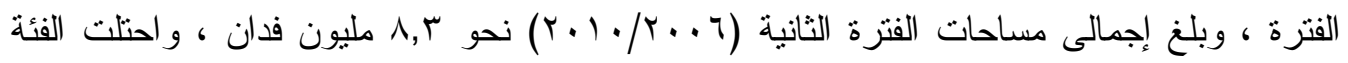

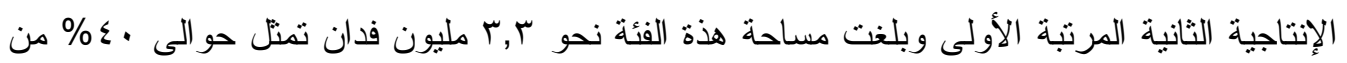
إجمالى مساحات تلك الفترة ، فى حين أحتلت الفئة الخامسة المرتبة الأخيرة وبلغت مساحة هذة ملثة الفئة

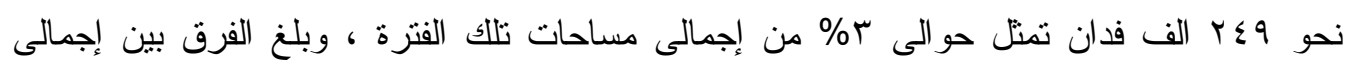

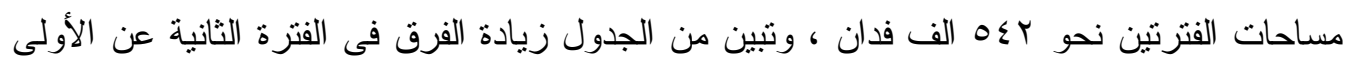

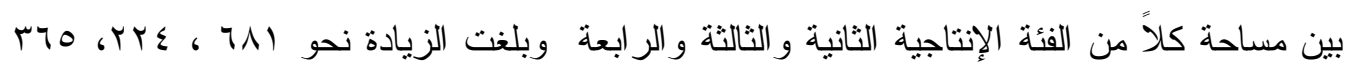

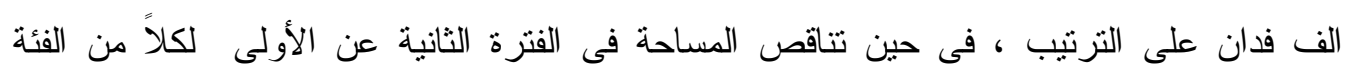

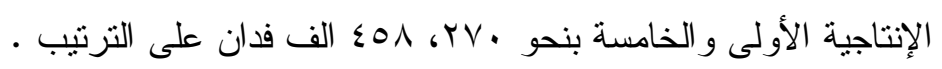

\section{جدول (Y) مساحات الرقعة الزراعية للمحاصيل الحقلية}

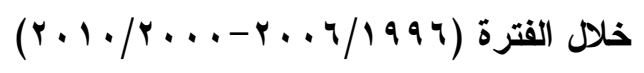

\begin{tabular}{|c|c|c|c|c|c|c|}
\hline \multirow{2}{*}{\multicolumn{2}{|c|}{ الفرق بين الفترتين }} & \multirow{2}{*}{\multicolumn{2}{|c|}{ 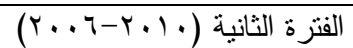 }} & \multirow{2}{*}{\multicolumn{2}{|c|}{ 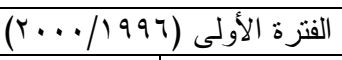 }} & \\
\hline & & & & & & \multirow[b]{2}{*}{ الإنتاجية } \\
\hline \% من إجمالى & المساحة & \% من إجمالى & المساحة & \% من & المساحة & \\
\hline$(\Sigma q, \wedge)$ & $(Y V \cdot)$ & rr & TVTE & $r \wedge$ & $r \ldots \varepsilon$ & الاولى \\
\hline $1 Y 0,7$ & 711 & $\varepsilon$. & 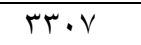 & $r \varepsilon$ & TTYT & الثانية \\
\hline$\varepsilon 1, r$ & TYE & 11 & $1 \leqslant V 7$ & 17 & TrOY & الثالثة \\
\hline$T V, r$ & r40 & v & $0 \wedge$. & $r$ & rio & الر ابعة \\
\hline$(\wedge \leqslant, 0)$ & $(\varepsilon 0 \wedge)$ & $r$ & $r \leq 9$ & 9 & $V \cdot V$ & الخامسة \\
\hline $1 \ldots$ & $0 \leqslant r$ & $1 \ldots$ & $\lambda \Gamma \leq T$ & $1 \ldots$ & $\vee \wedge \cdot \varepsilon$ & 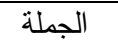 \\
\hline
\end{tabular}

*الأرقام بين الأقواس تعبر عن قيم سالبة.

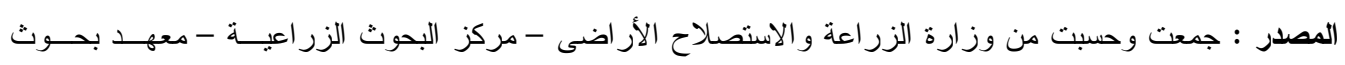

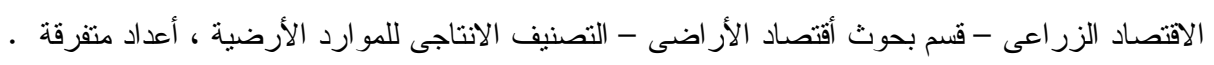

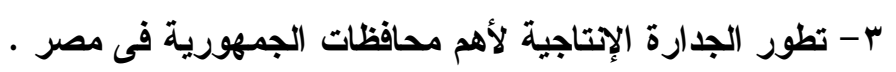

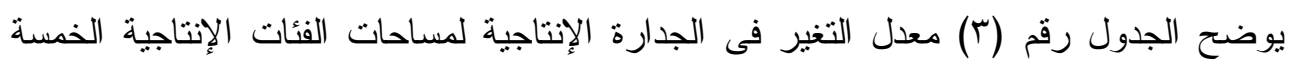

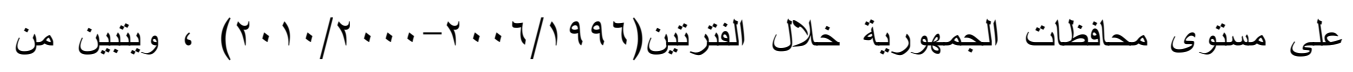

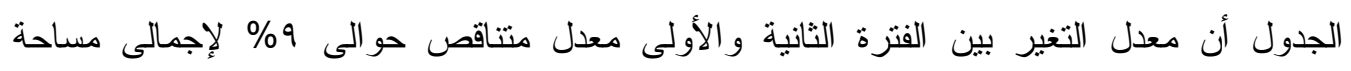

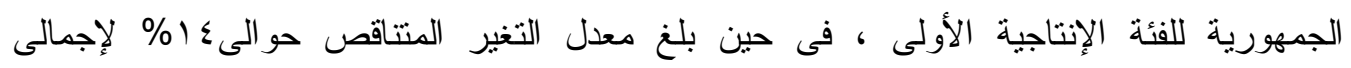

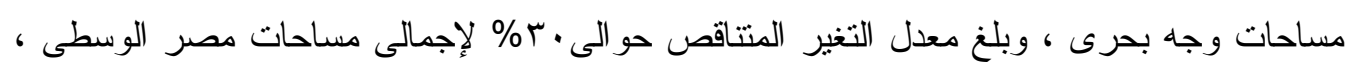

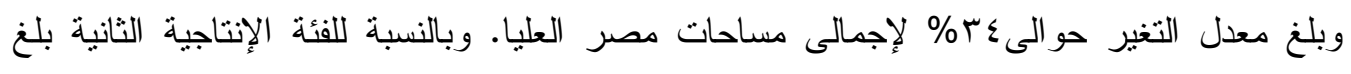

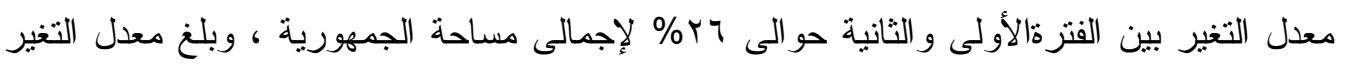

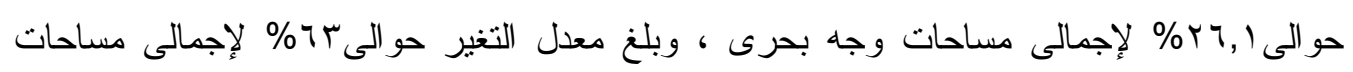

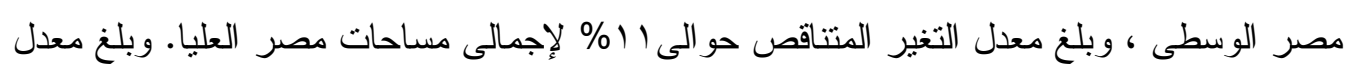

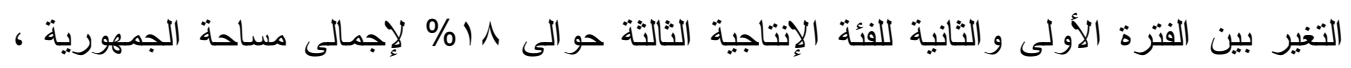

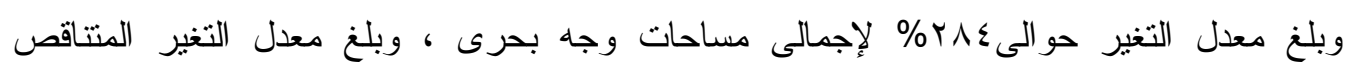




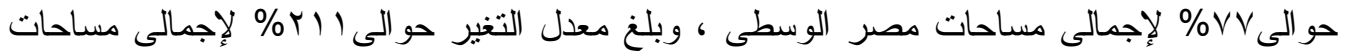

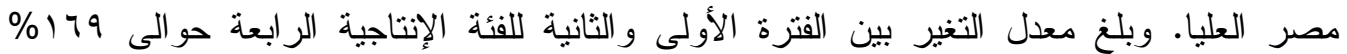
لإجمالى مساحة الجمهورية ، وبلغ معدل التغير حوالىع 99\% لإجمالى مساحات وجه بحرى . فى حين بلغ معدل التغير المتاقص بين الفترة الأولى والثانية للفئة الإنتاجية الخامسة حوالى 70\%

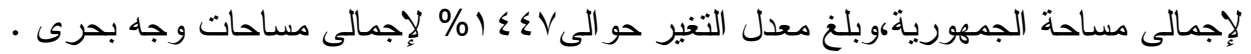

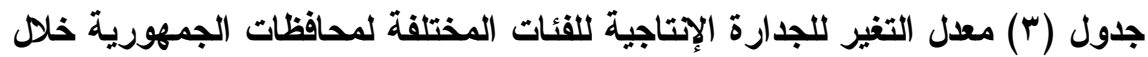

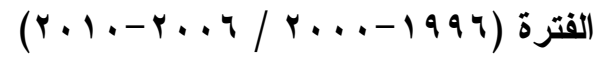

\begin{tabular}{|c|c|c|c|c|c|}
\hline الفئة الخامسة تغير & \% الفئة الر ابعة تغير & \% الفئة الثالثةل تغير & \% الفئة الثانية تغير & \% لمعدل تغير الأولى & المحافظات \\
\hline$\cdot$ & . & VVT & $(\wedge \cdot)$ & $(1 \cdots)$ & اسكندرية \\
\hline . & $1 \ldots$ & . & rAv & $7 \varepsilon$ & البحيرة \\
\hline • & $\cdot$ & · & $(\varepsilon 1)$ & 1 & الغربية \\
\hline . & • & $(1 \cdots)$ & $1 \ldots$ & $\left(r_{0}\right)$ & كفر الثيخ \\
\hline $1 \cdots$ & $\cdot$ & • & or & $\left(r^{q}\right)$ & الدقهلية \\
\hline . & $1 \ldots$ & . & $(\mathrm{VI})$ & rr & دمياط \\
\hline . & TIE & $1 \ldots$ & TVT & $(9 \varepsilon)$ & الشرقية \\
\hline · & $1 \cdots$ & $r V$ & $1 \cdots$ & $\cdot$ & الاسماعيلية \\
\hline · & $\cdot$ & $(1 \cdots)$ & $\cdot$ & • & بورسعيد \\
\hline · & • & $(09)$ & • & $1 \ldots$ & جملة السويس \\
\hline . & . & $\cdot$ & $(\varepsilon v)$ & $(1 \cdots)$ & المنوفية \\
\hline $1 \ldots$ & . & $(1 \cdots)$ & $r \leq$ & $(1 \cdots)$ & القليوبية \\
\hline$(r \wedge)$ & . & 11. & . & . & القاهرة \\
\hline $1 \leq \varepsilon \wedge$ & $99 \leq$ & TA乏 & rT & $(1 \varepsilon)$ & البحرى الوجها \\
\hline $1 \ldots$ & $1 \ldots$ & $1 \ldots$ & 1. & r & الجيزة \\
\hline . & . & $(1 \cdots)$ & 97 & $1 \ldots$ & بني سويف \\
\hline · & $1 \cdots$ & $(79)$ & ru & $1 \cdots$ & الفيوم \\
\hline . & $\cdot$ & $\cdot$ & $1 \cdot 1$ & $(7 \varepsilon)$ & المنيا \\
\hline $1 \cdots$ & $1 \cdots$ & $(\vee \top)$ & זיד & $(r \cdot)$ & اجمالى مصر \\
\hline$\cdot$ & · & · & $\leqslant 7$ & $(1 \cdots)$ & اسيوط \\
\hline . & . & $\cdot$ & (ro) & $1 \ldots$ & سوهاج \\
\hline . & . & $(1 \cdots)$ & $(\wedge \vee)$ & $V Y$ & قنا \\
\hline . & $\cdot$ & · & $\cdot$ & $1 \cdots$ & الاقصر \\
\hline • & $1 \cdots$ & $\varepsilon 7 \wedge$ & $\varepsilon \leqslant 7$ & (7) & اسو ان \\
\hline$\cdot$ & $1 \ldots$ & 111 & $(11)$ & $r \varepsilon$ & اجمالى مصر العليا \\
\hline$(1 \cdots)$ & $1 \ldots$ & $1 \cdots$ & . & $1 \cdots$ & الو ادي الجديد \\
\hline $1 \ldots$ & $1 \cdots$ & $1 \cdots$ & $\cdot$ & $\cdot$ & مطروح \\
\hline$\cdot$ & $\cdot$ & $1 \cdots$ & . & . & البحر الاحمر \\
\hline$(\vee \top)$ & $1 \cdots$ & $\cdot$ & • & · & شمال سيناء \\
\hline • & rav & $1 \cdots$ & $\cdot$ & • & جنوب سيناء \\
\hline$\cdot$ & $\cdot$ & $(\wedge \varepsilon)$ & $1 \cdots$ & $\cdot$ & النوبارية \\
\hline$(70)$ & 179 & 11 & $r 7$ & (9) & اجمالي الجمهورية \\
\hline
\end{tabular}

* * الأرقام بين الأقو اس تعبر عن قيم سالبة . 
ثانياً : التدهور النوعي فى الأراضى الزراعية :

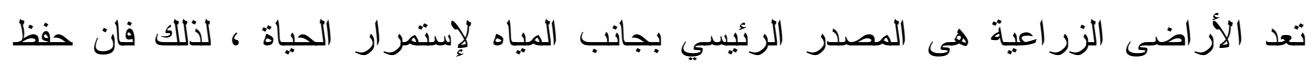

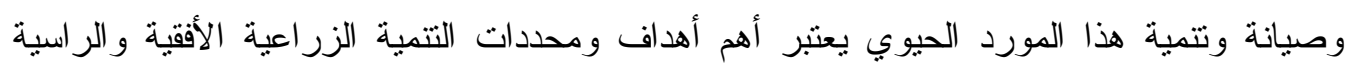

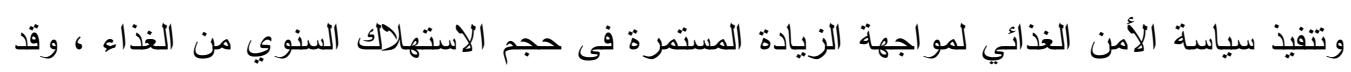

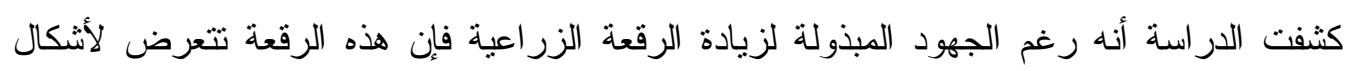

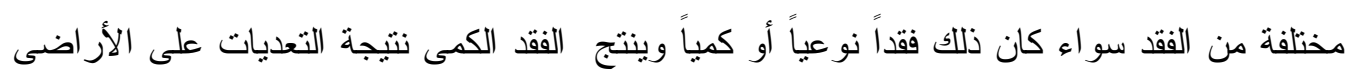

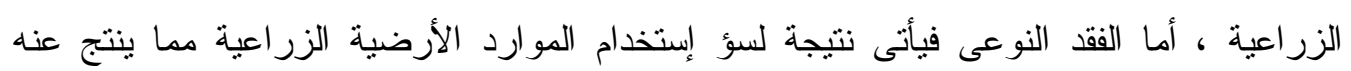

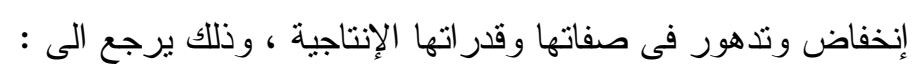

- عدم كفاءة عمليات الرى و الصرف وما يترنب عليها من زيادة فى درجة الملوحة أو القلوية.

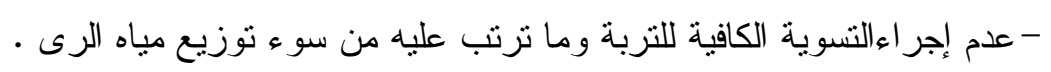

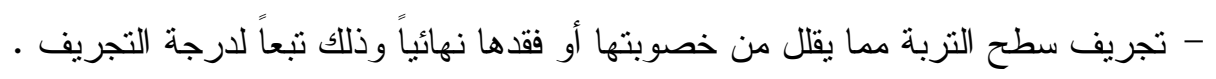

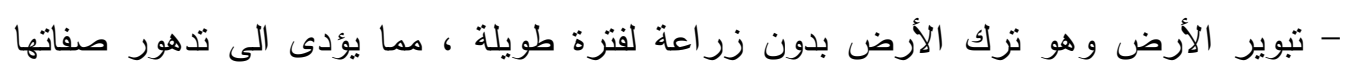
وضعف إنتاجها.

\section{أ- التدهور النوعي في الإراضى الزراعية على مستوى الجمهورية :}

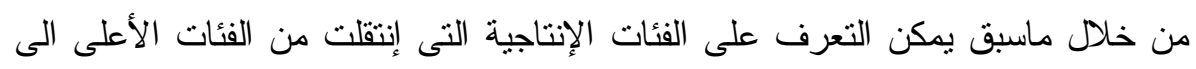

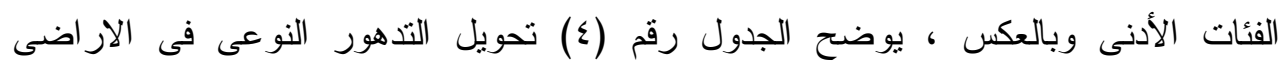

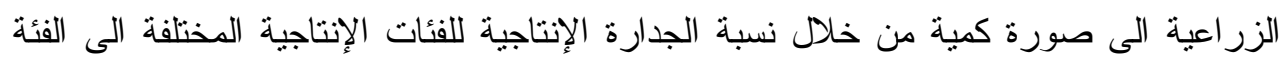
الإنتاجية الاولى حيث ان الإنخفاض الذى حدث فى مساحة أراضى الفئة الإنتاجية الأولى قابله

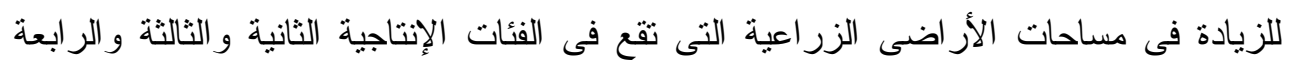
و الخامسة ، ويتبن من الجدول إنخفاض مساحة أراضى الفئة الإنتاجية الاولى ذات الإنى الإنتاجية

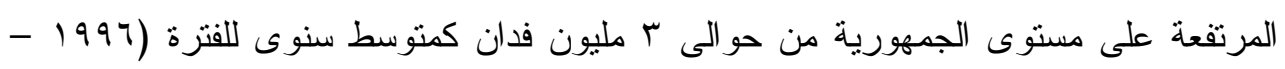

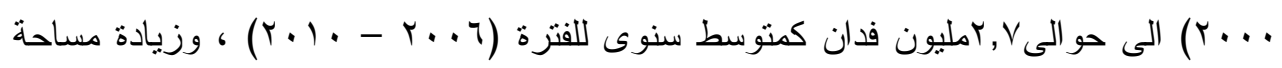

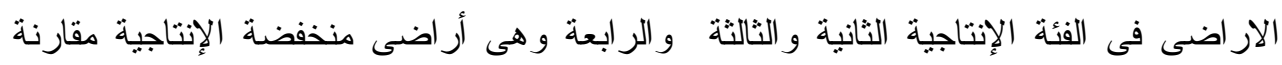

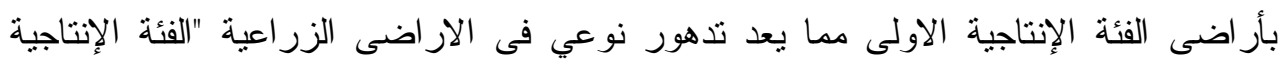

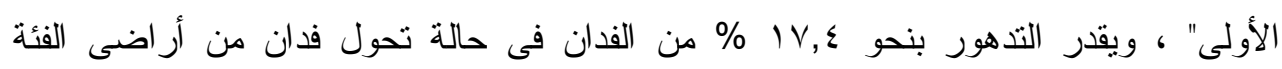

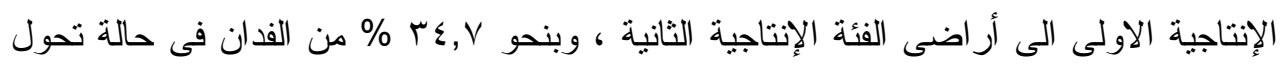

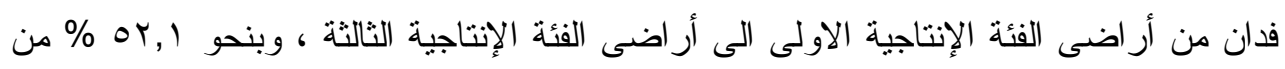

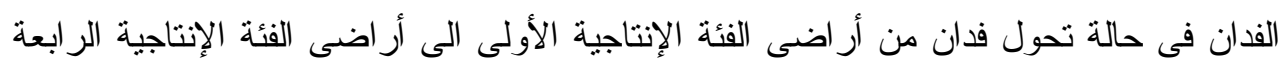

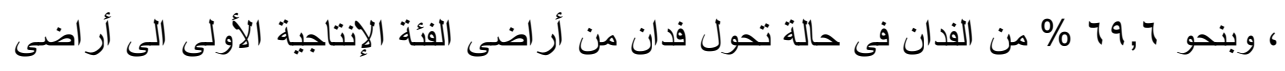

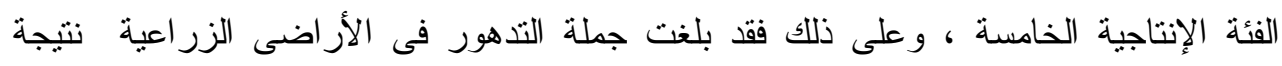

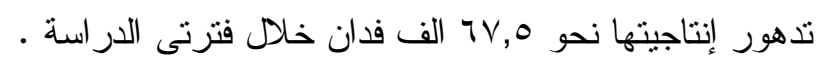




$$
\begin{aligned}
& \text { جلول ( ؛): التدهور النوعى لمساحة الاراضى الزراعية فى مصر }
\end{aligned}
$$

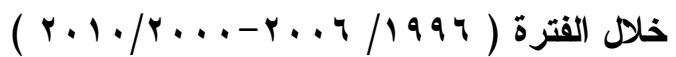

المساحة (الف فدان)

\begin{tabular}{|c|c|c|c|c|c|c|c|c|}
\hline حجم التذهور & نسبة التدهور & نسبة الفئات & مركز & الددى للفئة & التغير & $\begin{array}{l}-r . . T \\
r \cdot 1 .\end{array}$ & $\begin{array}{c}1997 \\
- \\
r \ldots .\end{array}$ & الفئة \\
\hline & & $1 \ldots$ & $\varepsilon, 7,0$ & $\varepsilon, r)-0$ & $(Y r \cdot)$ & TVTE & $r \ldots \varepsilon$ & الفئة الاولى \\
\hline$\| \Lambda, r$ & $\mid V, \varepsilon$ & $\Delta r, T$ & $r, A .0$ & $r, \varepsilon)-\varepsilon, r$ & 711 & r.V & דוצד & الفئة الثانية \\
\hline$V V, \wedge$ & $r \varepsilon, v$ & $70, r$ & $r, \ldots o$ & $r, 7)-r, \varepsilon$ & TrE & $1 \leqslant V 4$ & IrOT & الفئة الثالثة \\
\hline $19 \cdot, r$ & or, 1 & $\varepsilon v, q$ & T,Y.O & $1, \wedge 1-r, r$ & ryo & 01 . & rlo & القئة الر ابعة \\
\hline$(\Gamma \backslash \Lambda, \wedge)$ & 79,7 & $r \cdot, \varepsilon$ & $1, \varepsilon$ & $1-1,1$ & $(\{0 \wedge)$ & $r \leq 9$ & $v \cdot v$ & الخامسة \\
\hline$T V, O$ & & & & & $0 \leqslant Y$ & $\Delta r \leqslant T$ & $v \lambda \cdot \varepsilon$ & الجملة \\
\hline
\end{tabular}

الأرقام بين الأقو اس تعبر عن قيم سالبة .

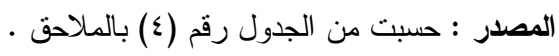

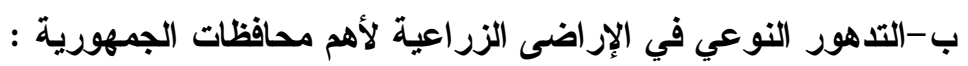

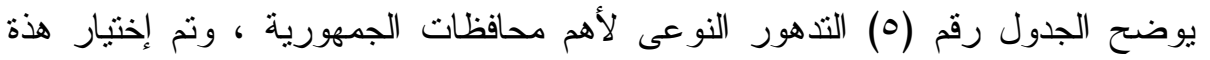
المحافظات على أساس الأهمية النسبية لمعدل التغير بين فترنى الدراسة ، وينتين من الجدول لأهن أن لتحويل التدهور النوعى فى الاراضى الزر اعية لأهم محافظات الجمهورية الى صورة كمية وذللك من خلال نسبة الجدارة الإنتاجية للفئات الإنتاجية المختلفة الى الفئة الإنتاجية الاولى حيث لإنى

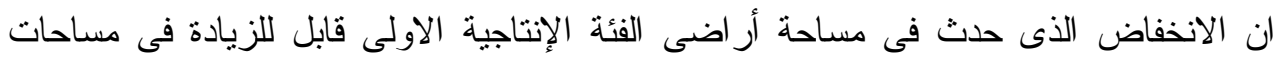

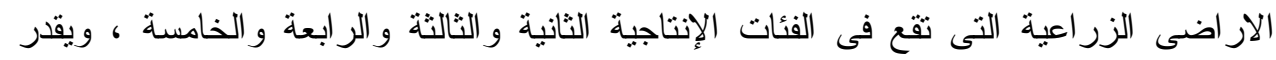

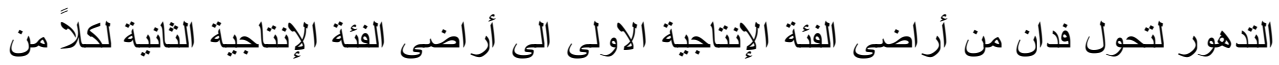

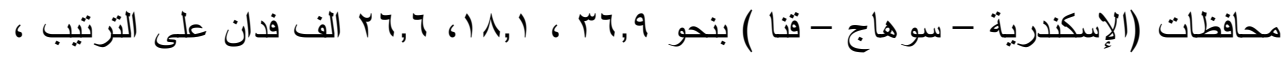
و فى حالة تحول فدان من أراضى الفئة الإنتاجية الاولى الى أر اضىى الفئة الإنتاجية الثالثة لكلاً

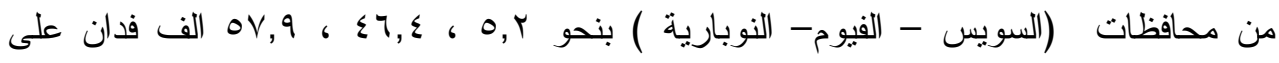
الترتيب ، و فى حالة تحول فدان من أراضى الفئة الإنتاجية الاولى الىى أراضى الفئة الإنتاجية

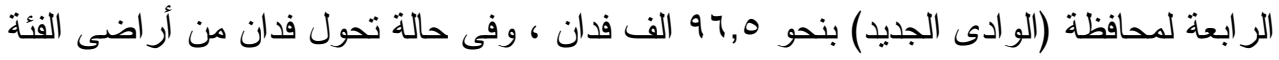
الإنتاجية الاولى الى أر اضى الفئة الإنتاجية الخامسة لكلاً من محافظات (شمال سيناء- القاهرة)

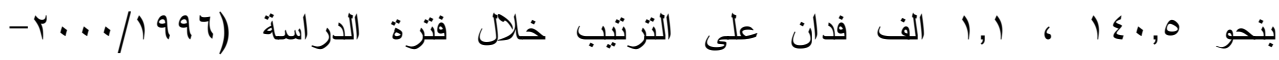




\section{جدول(ه): التدهور النوعى لمساحة الاراضى الزراعية لأهم محافظات الجمهورية

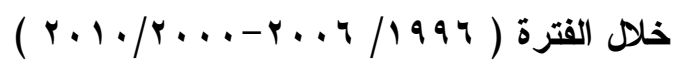

المساحة (الف فدان)

\begin{tabular}{|c|c|c|c|c|c|c|c|c|c|}
\hline لالنّهر & نسبة التهور النوعى & 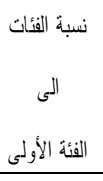 & الفئة & الدىى للثئة & التغير & $\begin{array}{l}-r . .4 \\
r .1 .\end{array}$ & $\begin{array}{l}-1997 \\
r \ldots\end{array}$ & الدافظظات & الفئة \\
\hline & & 1.. & $\{, 7.0$ & $\varepsilon, r)-0$ & $\begin{array}{l}(Y \varepsilon) \\
(\text { (Yq ) } \\
(\text { IYv }) \\
(99)\end{array}$ & $\begin{array}{l}\cdot \\
r \xi, Y \\
q Y, Y \\
\cdot\end{array}$ & $\begin{array}{l}1 \leqslant \\
\leqslant Y 1, Y \\
Y Y \varepsilon, Y \\
99\end{array}$ & 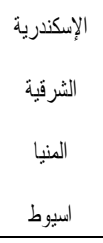 & الالولى الثئة \\
\hline $\begin{array}{l}(4,9,9) \\
(1 \times, 1) \\
(19,9)\end{array}$ & $1 v, \varepsilon$ & $\lambda r, Y$ & $r, \lambda, 0$ & $r, \xi 1-\xi, r$ & $\begin{array}{l}(r), r) \\
(1, \varepsilon, r) \\
(1 \circ r)\end{array}$ & $\begin{array}{c}o r, A \\
191, \varepsilon \\
r r \\
\end{array}$ & $\begin{array}{l}r y \varepsilon \\
r 90,1 \\
1 \times 4\end{array}$ & لموناج الإسكندرية & الثانية \\
\hline $\begin{array}{l}(0, Y) \\
(\& \square, \varepsilon) \\
(0 \vee, 9) \\
\end{array}$ & $r \varepsilon, Y$ & $r 0, r$ & $r, \ldots$ & $r, r)-r, \xi$ & $\begin{array}{c}(10) \\
(1 \times r, 4) \\
(177,9) \\
\end{array}$ & $\begin{array}{l}1 \cdot, 0 \\
1 \cdot, 1 \\
91 \\
\end{array}$ & $\begin{array}{l}r 0,0 \\
19 r, Y \\
r Y \varepsilon, 9 \\
\end{array}$ & النفوئ النوبر & الثالئة \\
\hline$(97,0)$ & or, & $\{v, q$ & $r, Y \cdot O$ & $(, A)-r, Y$ & $(1 \wedge 0, Y)$ & . & $110, r$ & 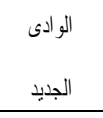 & اللزائة \\
\hline $\begin{array}{l}(1\{0,0) \\
(1,1)\end{array}$ & 79,1 & $r_{0, \xi}$ & 1,8 & $1-1, \AA$ & $\begin{array}{l}(r \cdot 1,9) \\
(1,7)\end{array}$ & $\begin{array}{l}r \xi, Y \\
r, Y \\
\end{array}$ & $\begin{array}{c}r 4 \%, 0 \\
\varepsilon, Y \\
\end{array}$ & شمال سيناء & الخاسسة \\
\hline
\end{tabular}

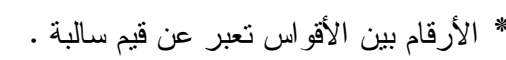

المصدر : حسبت من الجدول رقم (ع) بالملاحق .

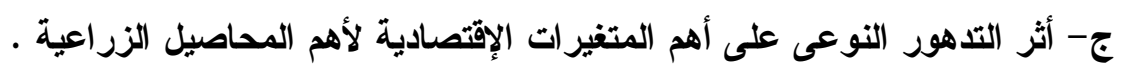
ا - إثر التدهور النوعى على صافى الاخل لأهم المحاصيل الزراعية :

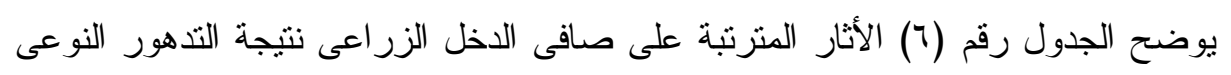

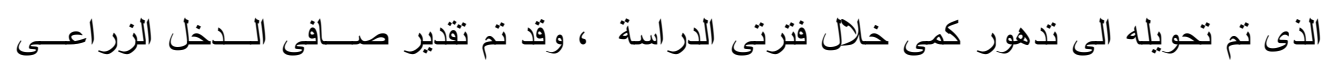

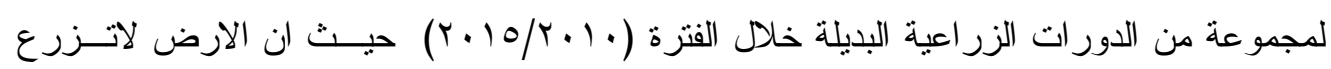

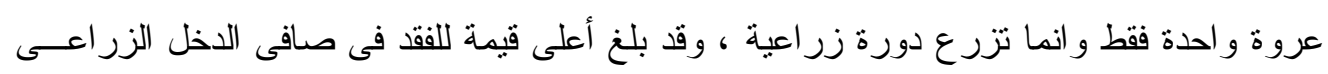

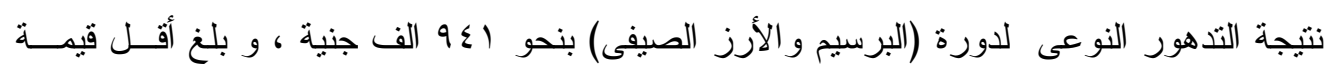

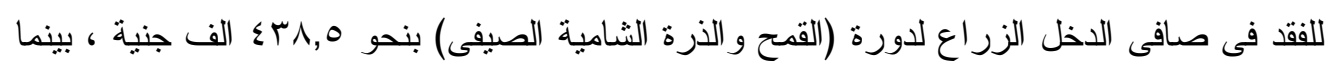

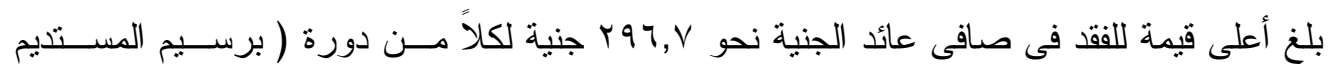

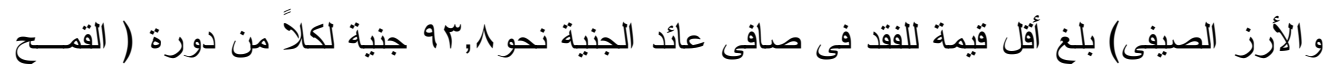


جدول (†): أثر التدهور النوعى على صافى العائد وصافى عائد الجنية

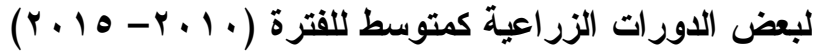

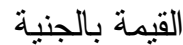

\begin{tabular}{|c|c|c|c|c|}
\hline صافى عائد & صافى عائد & الققد فى صافى & صافى العائد & الدورة الزر اعية \\
\hline$q \Gamma, \wedge r$ & $1, r q$ & 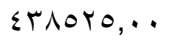 & $7 \leq 97,7 \vee$ & قمح + ذرة شامية صيفى \\
\hline$\cdots, \leq 7$ & $1, \leqslant 9$ & 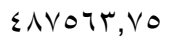 & VYYT,IV & قمح + الأرز صيفى \\
\hline$r q \cdot, \cdot r$ & $\varepsilon, \Gamma$. & $\wedge 9 r_{1} \cdot 1, r_{0}$ & $|r r| \leq, \wedge r$ & برسيم مستديم + ذرة شامية صيفى \\
\hline Y97,77 & $\varepsilon, \varepsilon \cdot$ & $q \leq 1, \leq \cdot, \ldots$ & $149 \varepsilon 1, r \pi$ & برسيم مستديم + الأرز صيفى \\
\hline$r \cdot 1, \lambda r$ & $r, 99$ & $\Lambda \cdot r \cdot \leq \vee, O$. & $11 \wedge 9 \vee, \ldots$ & بصل شتوى + ذرة شامية صيفى \\
\hline$Y \cdot \Lambda, \leqslant T$ & $r, .9$ & NOY.NT,YO & IrTrr,o. & بصل شتوى + الأرز صيفى \\
\hline
\end{tabular}

المصدر : جمعت و حسبت من الجدول رقم (1) بالملاحق .

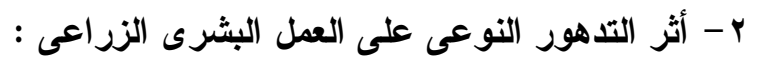

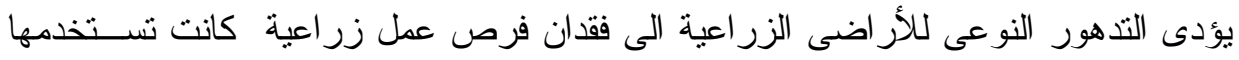

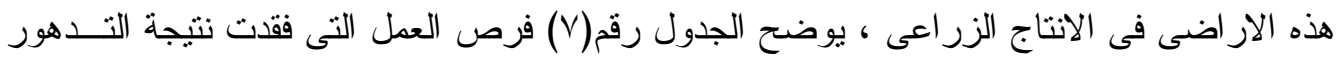

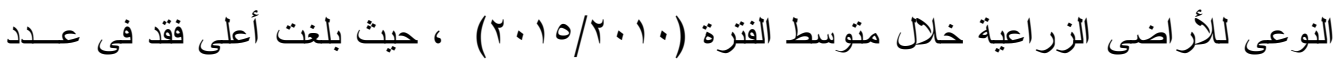

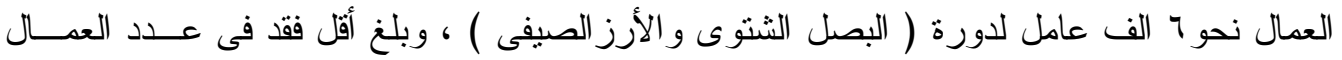
نحو r الف عامل لدورة (القمح و الذرة الثامية الصيفية) . جدول (v): اثر التدهور النوعى على العمالة الزراعية وفقا لاحتياجات

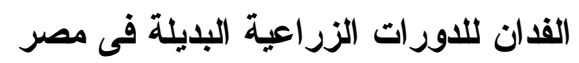

\begin{tabular}{|c|c|c|}
\hline 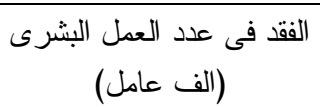 & عدد العمل البشرى & الدورة الزر اعية \\
\hline r. IV, ro & $\varepsilon \varepsilon, V$ & قمح + ذرة شامية صيفى \\
\hline סודיז & $\varepsilon 9, \wedge$ & قمح + الأرز صيفى \\
\hline MIVq,Yo & $\varepsilon \vee, 1$ & برسيم مستديم + ذرة شامية صيفى \\
\hline rorr,o & or, r & برسيم مستديم + الأرز صيفى \\
\hline $07 \vee 7, \vee \vee 0$ & $\wedge \varepsilon, 1$ & بصل شتوى + ذرة شامية صيفى \\
\hline $7 . Y_{1}$ & $\wedge 9, r$ & بصل شتوى + الأرز صيفى \\
\hline
\end{tabular}
المصدر :جمعت و حسبت من الجدول رقم (Y) بالملاحق .

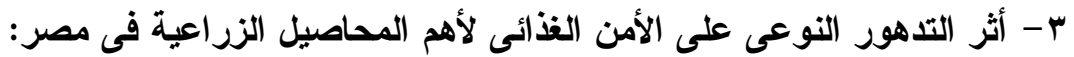

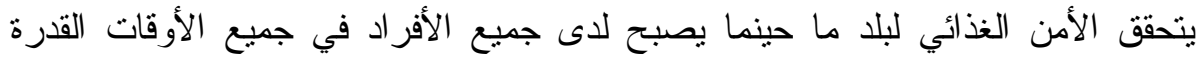
للحصول على الغذاء الكافي و الآمن بكامل عناصره الغذائية للوفاء باحتياجاتهم و أفضلياتهم الغذائية من أجل حياة نشطة وصحية ، و يتضح من ذلك أن مفهوم الأمن الغذائي مفهوم مركب لله أبعاد متعددة ويرتبط بتو افر أربعة شروط وهى الاتاحة سواء من المصادر المحلية أو الخارجية (و التي

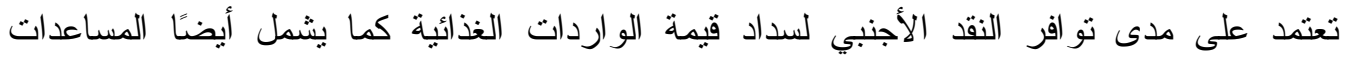
الغذائية) ، و الاستقر ار بمعنى ضرورة وجود مخزونات غذائية لتوفر الغذاء في جميع الأوقات خاصة بالنسبة للسلع الاستر اتيجية وفي مقدمتها الحبوب الغذائية لتجنب الصدمات المفاجئة (مثل الأزمات 
الاقتصادية أو المناخية او الثورات ..الخ) أو الأحداث الدورية (مثل انعدام الأمن الغذائي الموسمي) ، و الحصول على الغذاء والذى يرتبط بحصول جميع الأفراد على كمية من الغذاء الملائم لوجبه

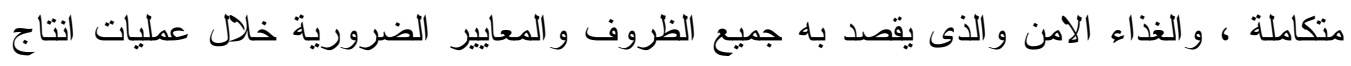
وتصنيع وتخزين و اعداد الغذاء اللازمة لضمان ان يكون الغذاء امنا وموثوقا به وصنهاء وصحيا وملائما

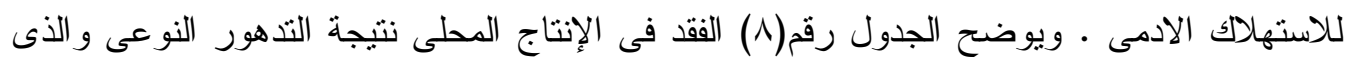

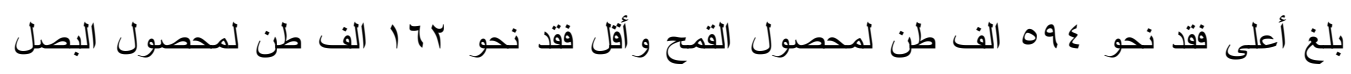

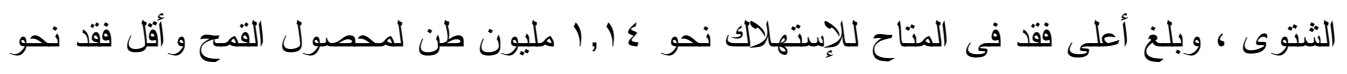

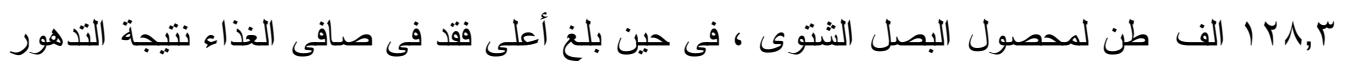

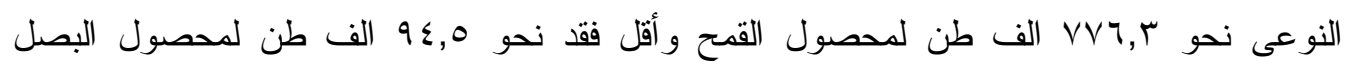

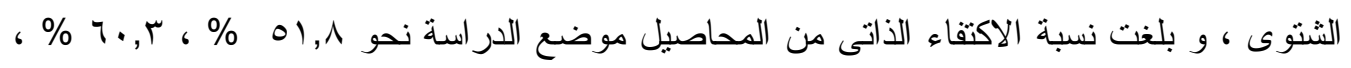

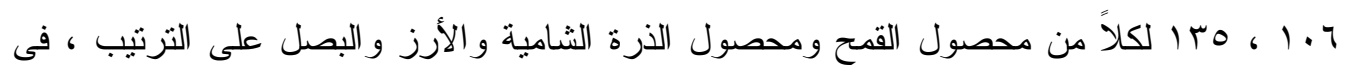

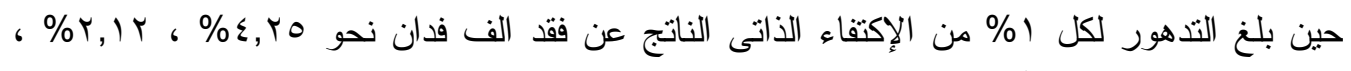

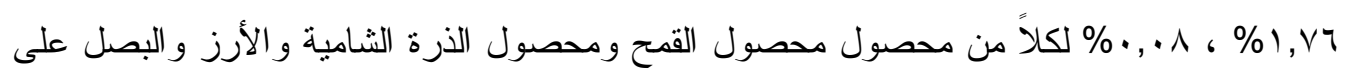
الترتيب

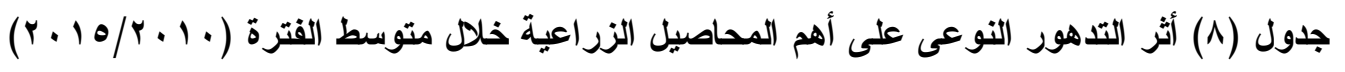

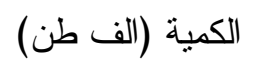

\begin{tabular}{|c|c|c|c|c|}
\hline البصل الشتوى & الأرز & الثامية & القمح & البيان \\
\hline $17 r, \cdot$. & $r \leqslant 9, V_{0}$ & $01 r, \cdot \cdot$ & $09 \xi, \cdot$ & التذهور فى الإنتاج المحلى \\
\hline IYA,YO & rol, . & $10 ., 0$ & $11 \leqslant \cdot, V_{0}$ & التذهور فى المتاح للإستهلاك \\
\hline $9 \leqslant, 0$. & $r r q, 0$. & Mчs,o. & $V V 7, Y_{0}$ & التذهور في صافى الغذاء \\
\hline 1ro & 1.4 & $r \cdot r$ & 01,1 & نسبة الإكتفاء الذاتى \\
\hline$\cdot, \cdot \wedge$ & $1, \mathrm{~V} 4$ & r,Ir & $\varepsilon, r_{0}$ & تدهور كل 1\% من الإكتفاء الذاتى نتيجة فقد الف فدان \\
\hline
\end{tabular}

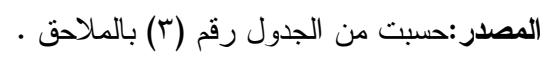

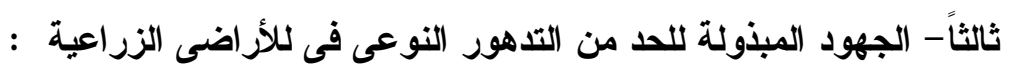
ا

يقصد بتحسين التربة خلق الظروف المثلى لنمو النباتات بمعالجة مشاكل تدهور التربة (الملوحة

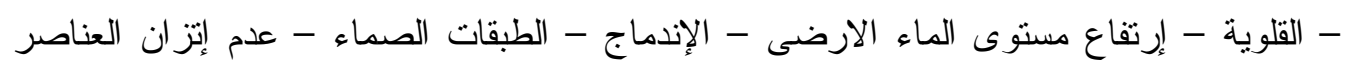

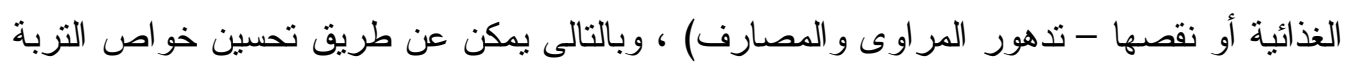

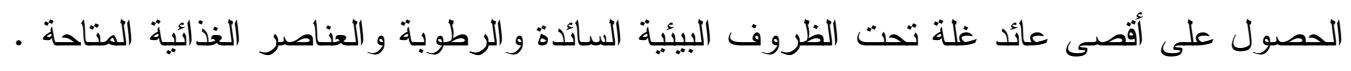

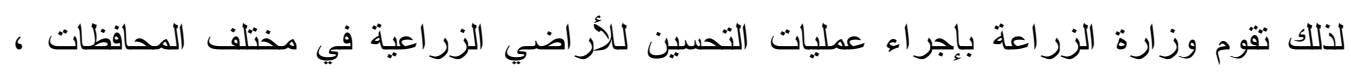

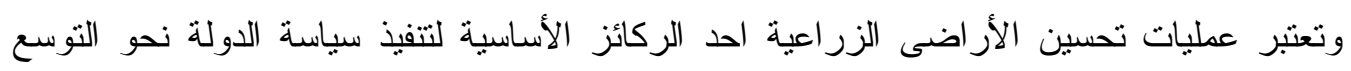

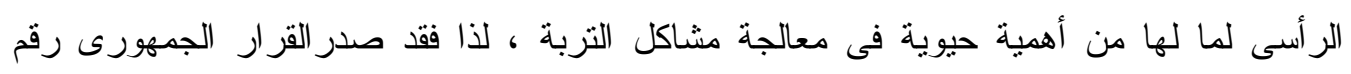

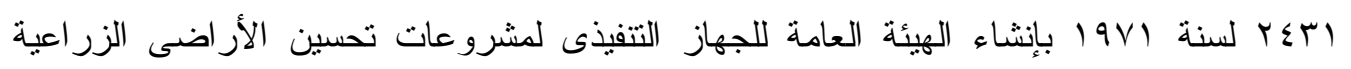


بقصد معالجة مشاكل تدهور التزبة الزراعية ورفع جدارنها الإنتاجية وذللك من خلال مراحل التحسين الأثية : التصنة معالجة

- إنثاء شبكات المصارف المكشوفة وتحديد مو اصفاتها تبعاً لدر اسات التربة.

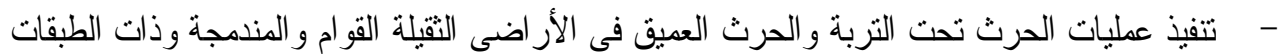
الصماء بهذف زيادة عمق الطبقة التى تعتبر المهز المناسب للنبات. - - - مإفة الجبس الزر اعى و التى تكفى لعلاج قلوية الطبقات السطحية من النزبة وتحسين حالة بنائها. - - غسيل الأملاح الضارة الز ائدة من قطاع التربة.

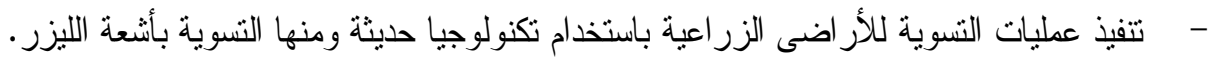

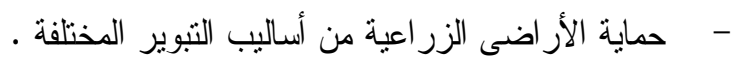

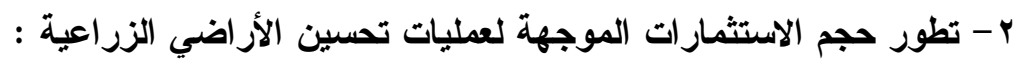
يوضح الجدول رقم (9) الإستتمارات الموجهة لعمليات تحسين الأر اضى الزر اعية فى الخطط الخطئ

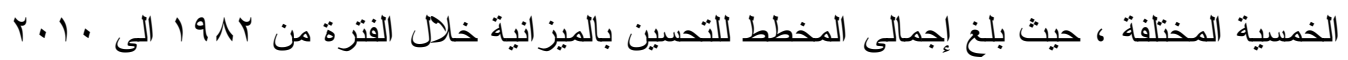

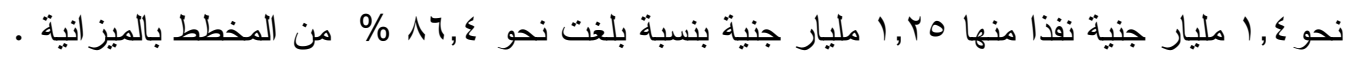

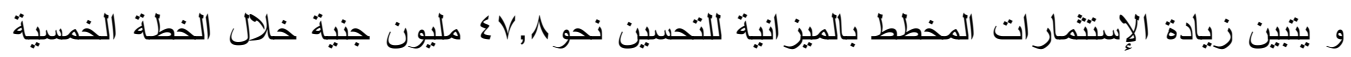

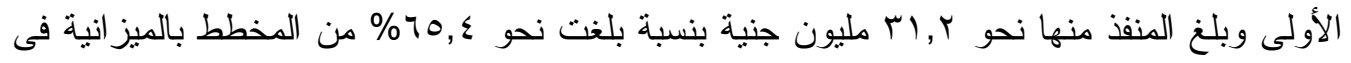

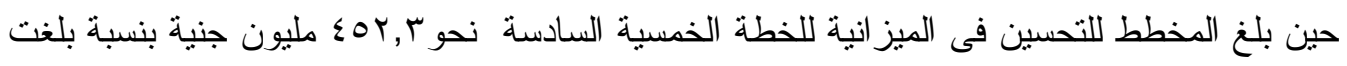
نحو 0 , 91 من المخطط بالميز انية. جدول (9): تطور حجم الاستثمارات لعمليات تحسين الأراضي الزراعية

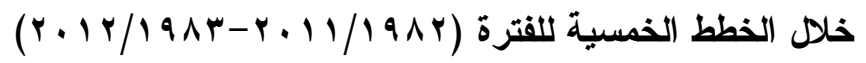

\begin{tabular}{|c|c|c|c|c|c|c|}
\hline \multirow{2}{*}{$\begin{array}{c}\text { المنفذ إلى } \\
\text { المخطط }\end{array}$} & \multicolumn{2}{|c|}{ المنفذ (المنصرف) } & \multicolumn{2}{|c|}{ المخطط بالميز انية } & \multirow[t]{2}{*}{ السنة المالبة } & \multirow[b]{2}{*}{ الحطة } \\
\hline & "الرقم القياسى & مليون جنبة & "الرقم القباسى & مليون جنية & & \\
\hline $10, \mathrm{r \Lambda}$ & $1 \cdots, \ldots$ & MI, Yr & $1 \cdots, \cdots$ & $\varepsilon V, V_{0}$ & $19 \Lambda V / \Lambda T-\Lambda r / \Lambda r$ & 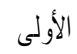 \\
\hline VI, Mr & YYO, qV & $V_{\cdot, O V}$ & $194, V$. & $q Y, \leqslant V$ & $199 r / 91-\Lambda \Lambda / \Lambda V$ & الثانية \\
\hline$\Lambda T, v T$ & 7 I $9,7 \varepsilon$ & $197, V$. & $\varepsilon q r, \ldots$ & $r r \varepsilon, q r$ & $1997 / 97-97 / 9 r$ & الثالثة \\
\hline $10, \cdot r$ & I. Mr,VY & M 9,7 . & VAV,r. & $r v 0, q r$ & $r \ldots r / \cdot 1-q \Lambda / q V$ & الر ابعة \\
\hline$\wedge q, \wedge \uparrow$ & $797, \leqslant \leqslant$ & YIY,VV & $0.0, r$. & $r \leq 1, r \leq$ & $r . . v / \cdot r-. r / \cdot r$ & الخامسة \\
\hline 91,01 & IrrT,O. & $\$ 1 \Upsilon, \Lambda\rceil$ & $q \leqslant V, 1 Y$ & sOr, YO & $\begin{array}{l}-. N / \cdot V \\
r .1 Y / \cdot 11\end{array}$ & السادسة \\
\hline$\Lambda\rceil, \varepsilon \varepsilon$ & $r q q r, \cdot V$ & $I r \leqslant \Lambda, V Y$ & $r \cdot r o, r t$ & $1 \leqslant \varepsilon \leqslant, 07$ & 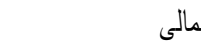 & \\
\hline$\Lambda\rceil, \leqslant \varepsilon$ & & $r \cdot \Lambda, 1 r$ & & $r \leq \cdot, V)$ & طط الخمسية & متوس \\
\hline$\Lambda \eta, \leqslant \varepsilon$ & & $r \xi, 79$ & & $\varepsilon \cdot, 1 \mu$ & $(19 \lambda r-r \cdot 1 r)$ & متوسط الا \\
\hline
\end{tabular}

"الرقم القياسي

"الخطة الخمسية السادسة أخر تقدير ات الخطط الإنتثمارية التى تتم كل خمس سنو ات .

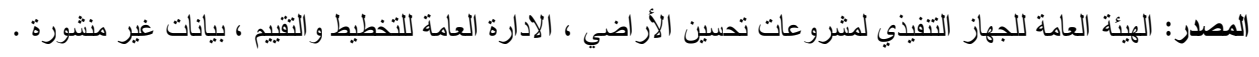




\section{ץ- إجمالى المساحات المنفذ بها عمليات تحسين الأراضى على مستوى الجمهورية :}

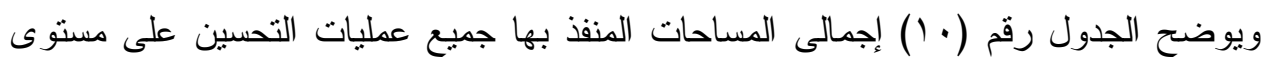

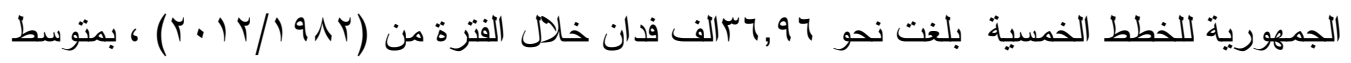

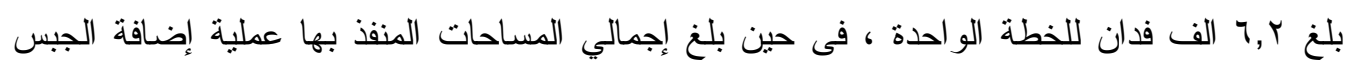

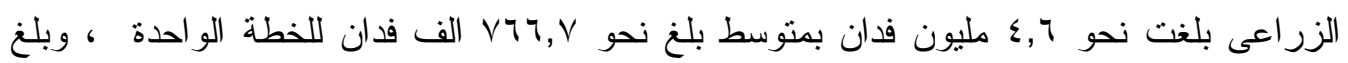

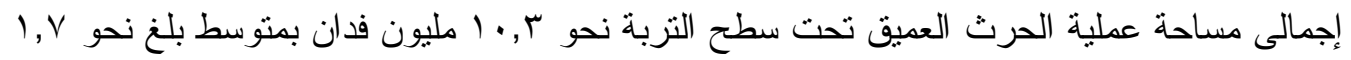

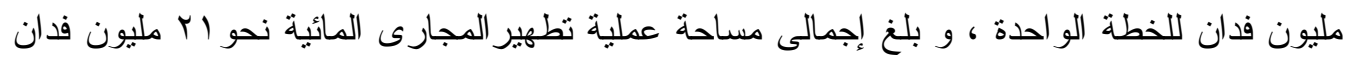

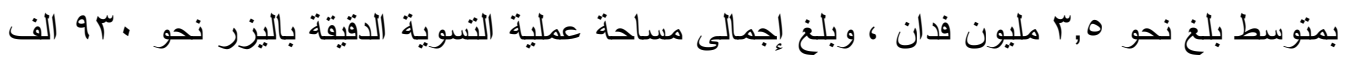

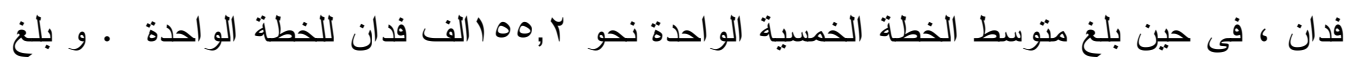

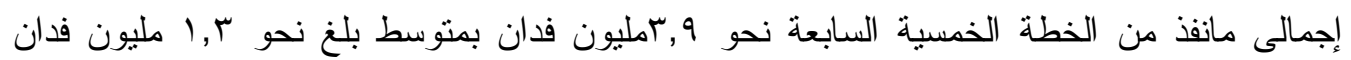

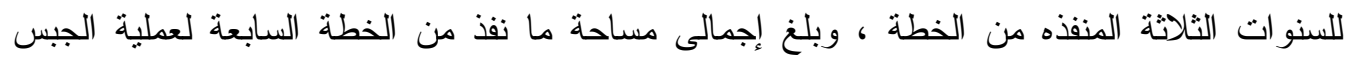

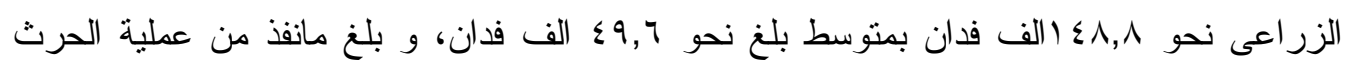
العميق تحت سطح التزبة نحو

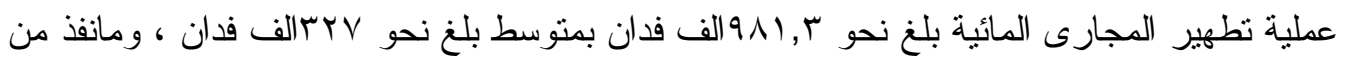

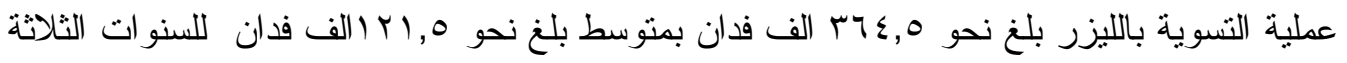

المنفذه من الخطة السابعة .

جدول (• (1): عمليات تحسين الأراضي الزراعية موزعة على برامج التحسين المختلفة

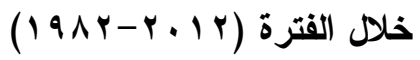

\begin{tabular}{|c|c|c|c|c|c|c|c|c|c|c|c|}
\hline \multicolumn{2}{|c|}{ إجمالي مساحات التحسين } & \multicolumn{2}{|c|}{ التسوية الاقيقة بالليزر } & \multicolumn{2}{|c|}{ المجاري المائية } & \multicolumn{2}{|c|}{ تحث التربة العيق } & \multicolumn{2}{|c|}{ الجبس الزرافاعي } & \multirow{2}{*}{ السنة المالية } & \multirow{2}{*}{ الخطة } \\
\hline$\%$ & ألف فدان & $\%$ & ألف فدان & $\%$ & ألف فدان & $\%$ & ألف فدان & $\%$ & ألف فدان & & \\
\hline$r, r$ & ITrT,Y & $\cdot, \cdot$ & $\cdot$, & $1, \varepsilon$ & $r \cdot 1, q$ & $r, q$ & $r q 9, \wedge$ & 11,0 & orl,1 & $\begin{array}{l}-\lambda Y / \lambda Y \\
19 \Lambda V / \Lambda T\end{array}$ & 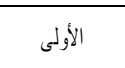 \\
\hline $1, \wedge$ & Y0.7, & $\cdot, Y$ & 7,1 & $r, 0$ & VYq & $V, \Lambda$ & $\Lambda \cdot 9,7$ & $r_{\cdot, q}$ & 971,8 & $\begin{array}{l}-\lambda N / \lambda V \\
199 Y / 91\end{array}$ & الثانية \\
\hline $1 \cdot, \cdot$ & rYvq,7 & $\{, 7$ & $\varepsilon r$ & $\mathrm{v}, \Lambda$ & 1747 & $1 Y, \Lambda$ & $1 \% 19,1$ & $1 \leqslant, 1$ & $7 x \cdot, 9$ & $\begin{array}{l}-9 Y / 9 Y \\
199 v / 97\end{array}$ & الثالثة \\
\hline$r \leqslant, 0$ & IrVTo,q & $1 r, 0$ & $1 \times 4,1$ & $r 0, \lambda$ & vort & MY,T & reto & $r v, r$ & 18.9 & $\begin{array}{l}-9 \Lambda / q Y \\
Y \ldots Y / \cdot .\end{array}$ & الر ابعة \\
\hline$r r, r$ & $119 \cdot 1,7$ & $r 1,9$ & $r \cdot r, Y$ & $r v$, & VA. & rT, r & rrta & Ir, r & $07 r, 9$ & $\begin{array}{l}-r r / r r \\
r . . v / . r\end{array}$ & الخامسة \\
\hline $1 r, r$ & $\{\wedge 9 \wedge, \cdot 1$ & $09, \Gamma$ & 001,71 & $1 \leqslant, 0$ & $r \cdot v \cdot, l$ & $1 \cdot, 9$ & $\| 1 Y 1, V$ & $r, \varepsilon$ & $10 \leqslant, 7$ & $\begin{array}{c}-\cdot N / \cdot r \\
r .1 r / \cdot 11\end{array}$ & السادسة \\
\hline \multirow[t]{2}{*}{$1 \cdots, \cdot$} & r9971,§। & $1, \cdot, \cdot$ & $94 \cdot, 91$ & $1 \cdots, \cdot$ & $r 11 \cdot V$ & $1 \cdots, \cdot$ & 1.rYT,q & $1 \cdots, \cdot$ & $\leqslant 099,9$ & & الإجمالي \\
\hline & $717, Y \leq$ & & 100,10 & & rolv,Ar & & IVY.,Y0 & & $V 71,70$ & & متّوسط الخطط \\
\hline rT,IT & IY9Y,VY & 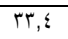 & $|Y|, Y$ & $r \cdot, 9$ & $r \cdot r, 0$ & $r, \Lambda$ & $1 \leqslant 0, r$ & 01,1 & $v_{0}, 91$ & $r .1 r / r .1 r$ & \multirow{3}{*}{ الخطة الخمسية } \\
\hline$\mu, 1 r$ & $|Y| \xi, Y A$ & $r \mu, \cdot$ & $M r, Y$ & $r \cdot r$ & $r 97,1$ & $r \Psi, V$ & $10 \leqslant,$. & $Y \leqslant, Y$ & $r \uparrow, \Lambda$ & $r .1 \leqslant / r .1 r$ & \\
\hline$r_{0, V O}$ & 11990,11 & $r r, q$ & $1 Y Y, T$ & $r \Lambda, 9$ & $r \wedge I, V$ & $\Gamma \leqslant, 0$ & $10 \%, r$ & $r \leqslant, Y$ & $r_{0,9 V}$ & $r .10 / Y .1 \varepsilon$ & \\
\hline \multirow[t]{2}{*}{$1 \ldots, \cdot$} & $r q . r, Y r$ & & Tצ,O & & $9 \wedge 1, r$ & & $\leqslant 07,0$ & & $1 \leqslant \Lambda, V_{0}$ & & 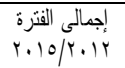 \\
\hline & $\mid r \ldots, v \leqslant$ & & $|r|, 0$. & & Trv,l. & & lor,IV & & $\{9,0 \wedge$ & & 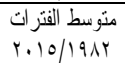 \\
\hline
\end{tabular}

المصدر : الهيئة العامة للجهاز التتفيذي لمشروعات تحسين الأر اضي ، الادارة العامة للتخطيط و التقييم ، بيانات غير منشورة. 


\section{ع - أثر التحسين على الإراضى الزراعية لأهم محافظات الجمهورية :}

يوضح الجدول رقم(1) التحسين الذى حدث لأهم محافظات الجمهورية خلال فترتى الدراسة

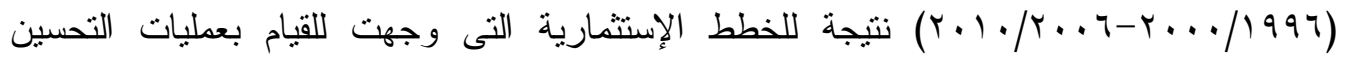
بمختلف محافظات الجمهورية ونم إختبار هذة المحافظات على أساس الأهمية النسبية لمعدل التغير

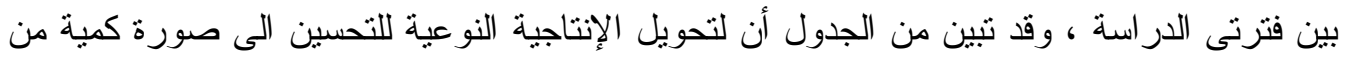
خلال نسبة الجدارة الإنتاجية للفئات الإنتاجية المختلفة الى الفئة الإنتاجية الاولى حيث ان الزيادة فى لهى

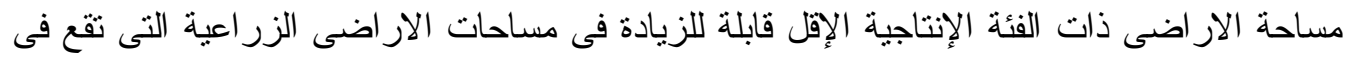
الفئات الإنتاجية الأعلى ، وقدر التحسين فى حالة تحول فدان من الار اضى ذات الفئة الإنتاجية الثانية

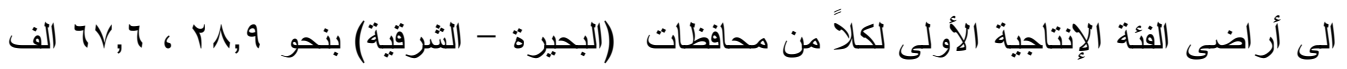

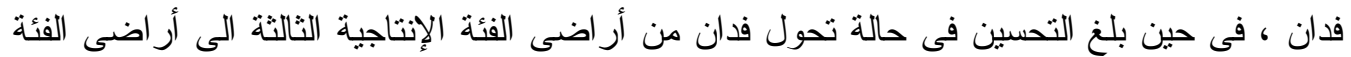

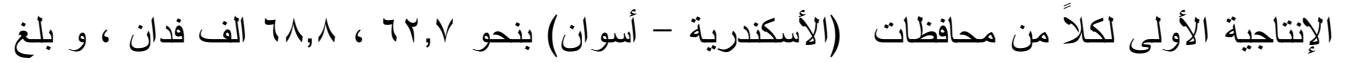

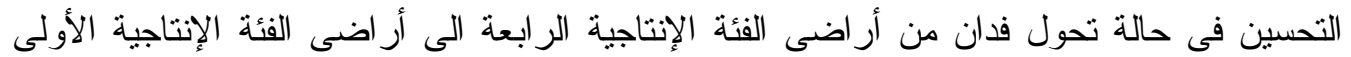

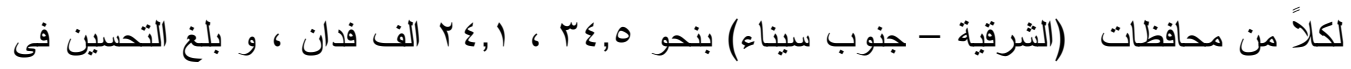
حالة تحول فدان من أراضى الفئة الإنتاجية الخامسة الى أر اضى الفئة الإنتاجية الأولى لكلاً من أنساء

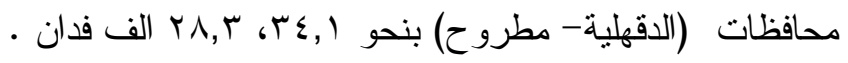

\section{جلول( 11 ): التحسين فى مساحة الاراضى الزراعيةلأهم محافظات الجمهورية

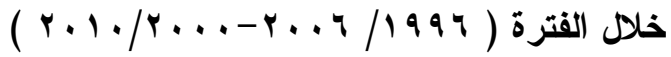

المساحة (الف فدان)

\begin{tabular}{|c|c|c|c|c|c|c|c|c|c|}
\hline حجم الفاقد & نسبة القاقد النوعى اللفئة الاولى & نسبة الفئات & مركز الفئة & المدى للفئة & التغير & $\begin{array}{c}r \ldots r \\
- \\
r .1 .\end{array}$ & $\begin{array}{c}1997 \\
- \\
r \ldots .\end{array}$ & المحافظات & الفئة \\
\hline & & $1 \ldots$ & $\{, 7,0$ & $\varepsilon, Y Y-0$ & $\begin{array}{l}r r, v \\
\Delta r\end{array}$ & $\begin{array}{c}09 \\
r .0,9\end{array}$ & $\begin{array}{l}r 0, r \\
119, q\end{array}$ & دمياط & الفئة الاولى \\
\hline $\begin{array}{l}r \wedge, q \\
Y Y, T\end{array}$ & $\mid v, \xi$ & $\Delta Y, Y$ & $r, A \cdot 0$ & $r, \varepsilon)-\varepsilon, r$ & $\begin{array}{l}147, r \\
r \Lambda, r\end{array}$ & $\begin{array}{l}r \cdot q, r \\
\leq \leqslant 4\end{array}$ & $\begin{array}{l}\varepsilon r \\
v_{0, Y}\end{array}$ & البحرية البحة & الفئة الثانية \\
\hline $\begin{array}{l}r r, Y \\
r \Lambda, \lambda\end{array}$ & $r \xi, v$ & $10, r$ & $r, \ldots o$ & $r, T)-r,\{$ & $\begin{array}{l}1 \lambda \cdot, \lambda \\
191, \varepsilon\end{array}$ & $\begin{array}{l}r \cdot \varepsilon, r \\
r \leqslant \cdot, \wedge\end{array}$ & $\begin{array}{l}r r, \varepsilon \\
\varepsilon r, \xi\end{array}$ & أسو أسندرية & الفئة الثالثة \\
\hline $\begin{array}{l}r \leqslant, 0 \\
r \leqslant, 1\end{array}$ & or, 1 & $\varepsilon v, q$ & T,Y.O & $1, \Lambda 1-r, r$ & $\begin{array}{l}77, r \\
\leq 7, r\end{array}$ & $\begin{array}{l}\varepsilon \lambda, 0 \\
0 \wedge\end{array}$ & $\begin{array}{l}11, r \\
11, Y\end{array}$ & جنوب سيناء & القئة الر ابعة \\
\hline $\begin{array}{l}r \varepsilon, r \\
r \Lambda, r\end{array}$ & 79,7 & $r \cdot$, & $1, \varepsilon$ & $1-1,1$ & $\begin{array}{l}\leq q \\
\varepsilon \cdot, V\end{array}$ & $\begin{array}{l}\varepsilon q \\
\varepsilon \cdot, \gamma\end{array}$ & . & مطروح الدقهلية & الخامسة \\
\hline
\end{tabular}

المصدر : حسبت من الجدول رقم (ع) بالملاحق .

\section{الملخص}

أستهدف البحث التعرف علي التدهور النوعى الذى طر أ على الجدارة الإنتاجية للمر اكز المختلفة على مستوى الجمهورية للمساعدة فى إعداد خطط وبر امج تحسين وصيانة للتربة الزر اعية والتى

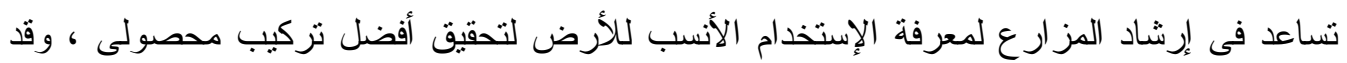

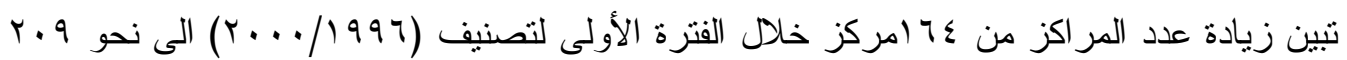




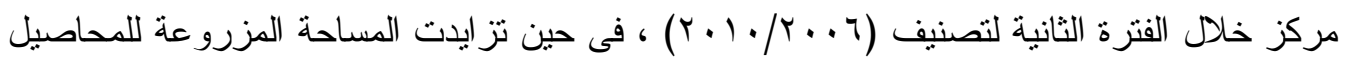

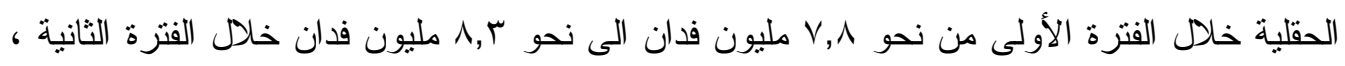

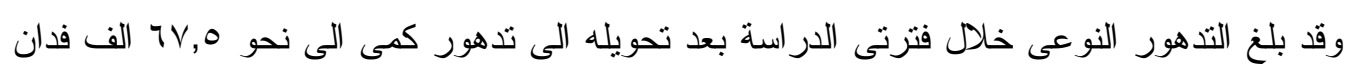

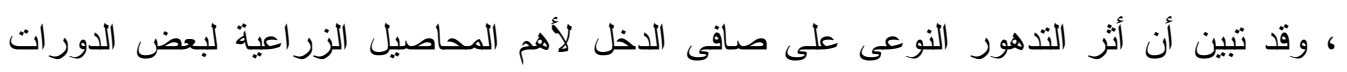

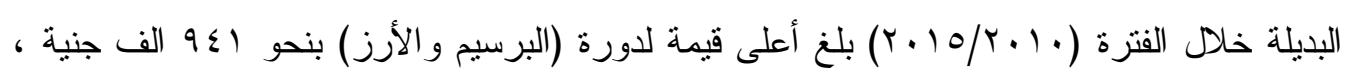

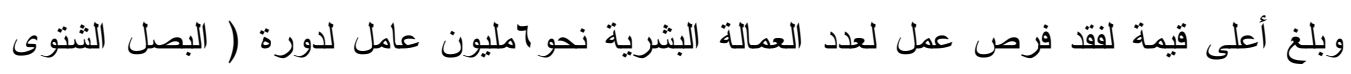

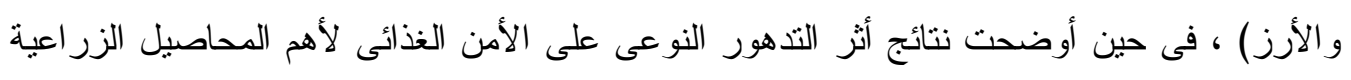

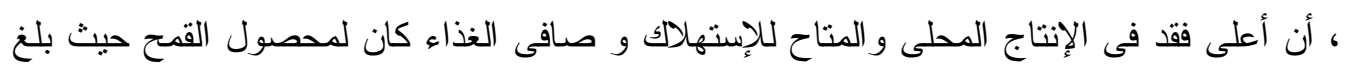

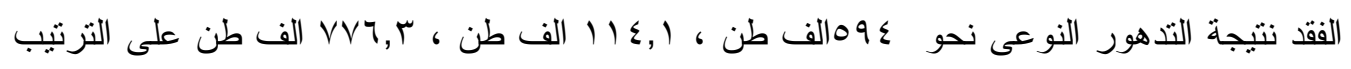

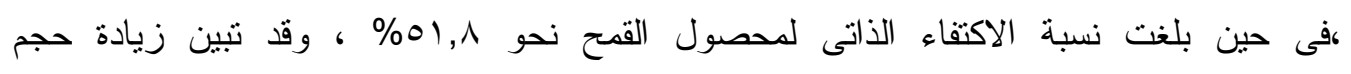

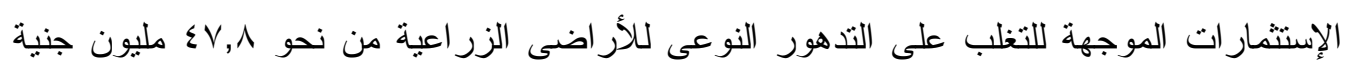

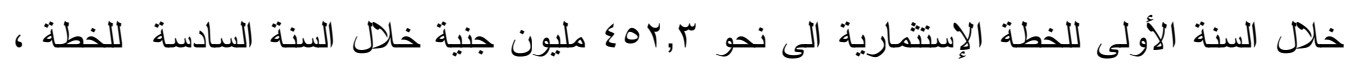

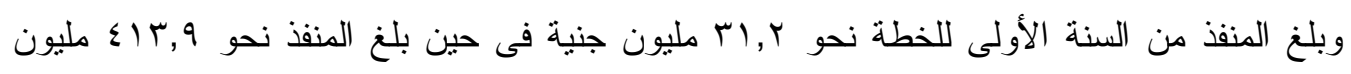

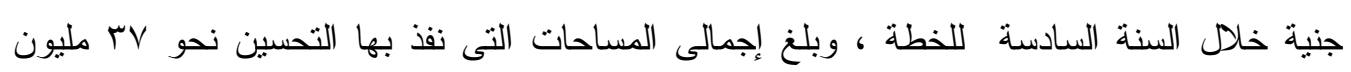

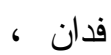

\section{التوصيات}

في ضوء النتائج المتحصل عليها يوصى البحث بأهمية العمل على وضع خطة منكاملة للتوسع فى مئى برامج التحسين المختلفة على مستوى جميع محافظات الجمهورية ونتجيع و زيادة الإستثمارات

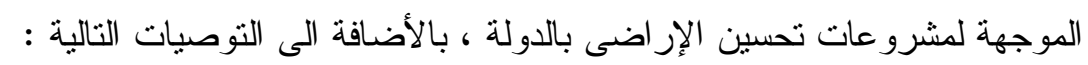

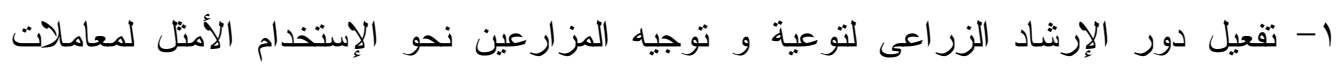
التحسين المختلفة نحو أر اضيهم الزر اعية .

r- تفعيل دور جهاز تحسين الأراضى كما كان فى السابق بأجر اء تحاليل التربة اللازمة لمعرفة أسباب تدهور التزبة الزراعية و التعرف على صفاتها وقدرتها الإنتاجية وبالتالى إتباع معاملات

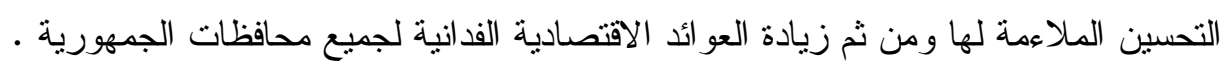

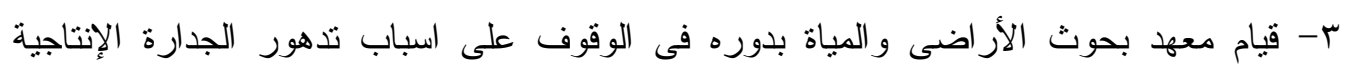

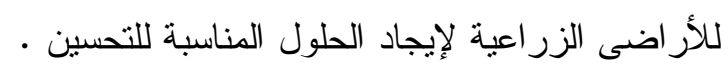
ع- أهمية العمل على وضع خطة متكاملة للتوسع فى برامج التحسين المختلفة على مستوى جميع

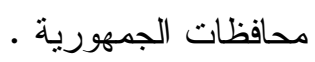
0- تشجيع و زيادة الإستثمار ات الموجهة لمشرو عات تحسين الإر اضى بالدولة .

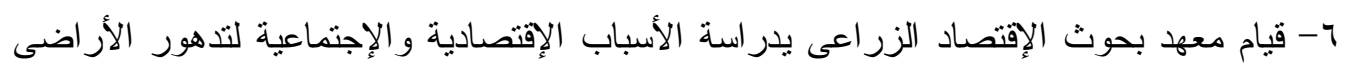

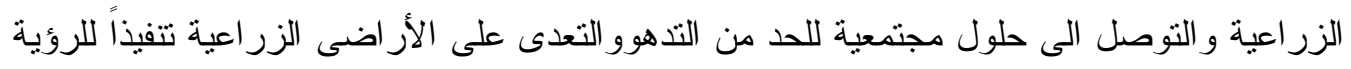

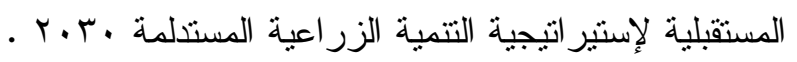




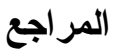

1- امل عبدالعظيم محمد ، اسماء صالح عبد المنعم "أثر تتفيذ برامج تحسين الأر اضى الزر اعية

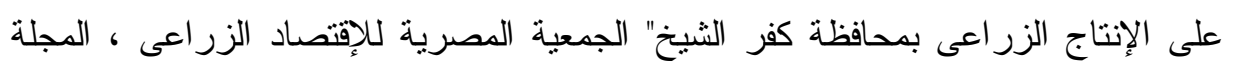

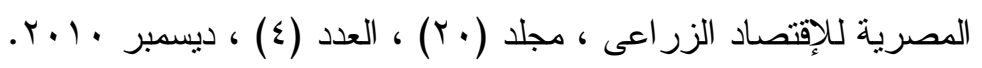

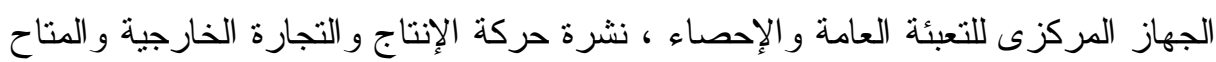

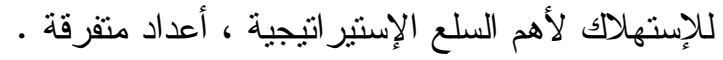

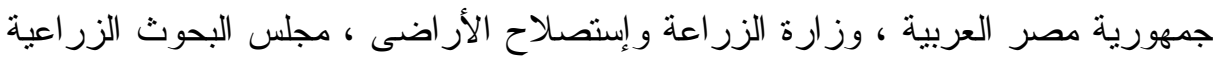

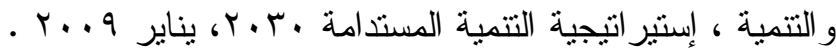

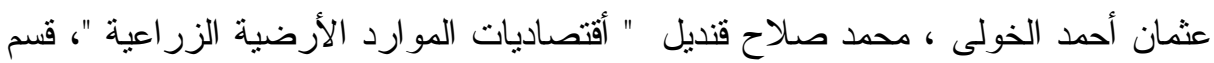

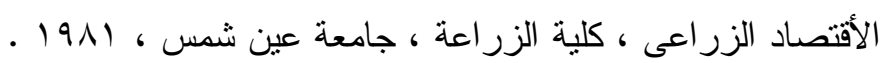

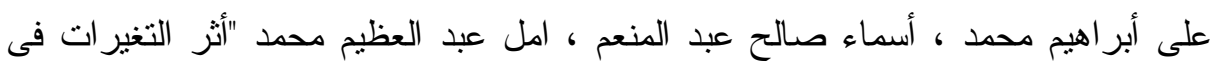

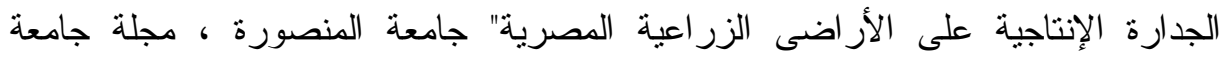

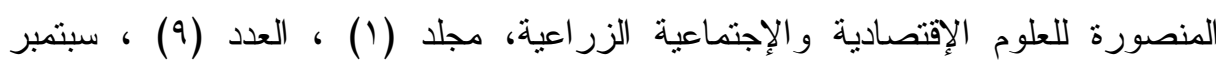

على عبدالمحسن على وأخرين "دراسة افتصادية لأثر تتفيذ برامج تحسين الأراضي

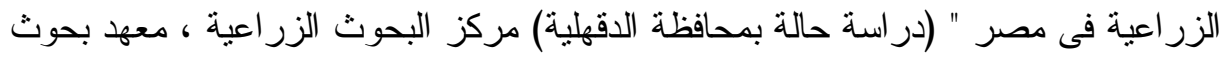

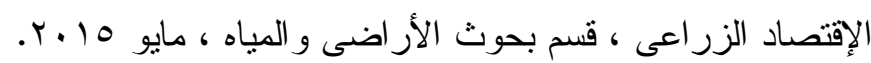

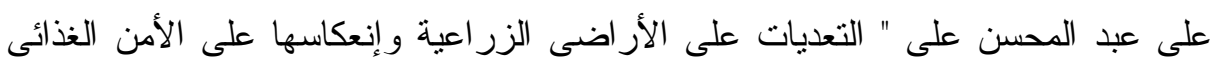

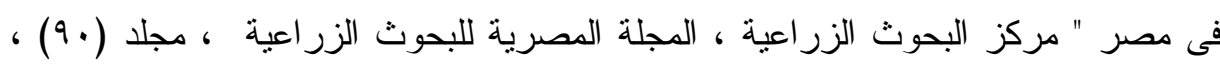

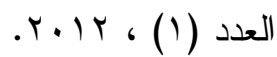
محمد سمير حسنى، محمود محمد عبد الفتاح " ثقييم القدرة الإنتاجية للأر اضى الزر اعية

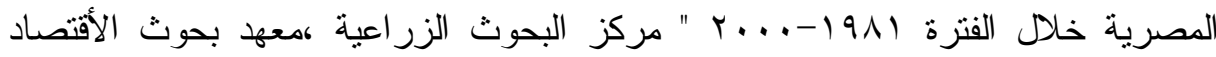

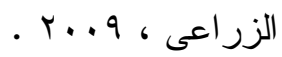
مركز البحوث الزر اعية ، معهد بحوث الأقتصاد الزراعى- قسم بحوث إقتصاد الاراضى ،

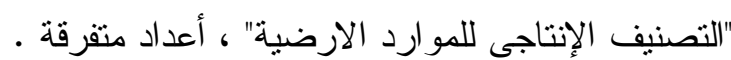

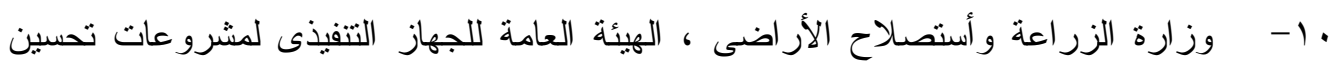

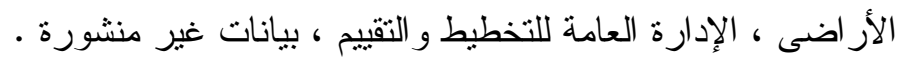
وزارة الزر اعة وأستصلاح الأراضى ، قطاع الأرة الشئون الأقتصادية ، نشرة المعاملات الفنية

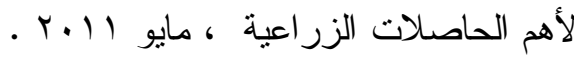

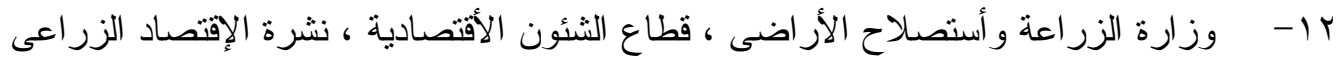

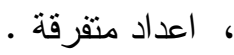
با - وزارة الزر اعة وأستصلاح الأراضى ، قطاع الثئون الأقتصادية ، نشرة الاحصاءات

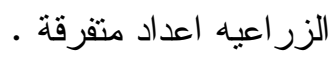
؛ 1 - وزارة الزراعة وأستصلاح الأراضى ، الهيئة العامة للجهاز التنفيذى لمشروعات تحسين

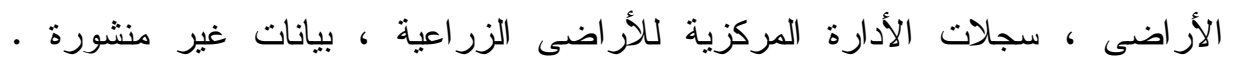




\section{الملاحق}

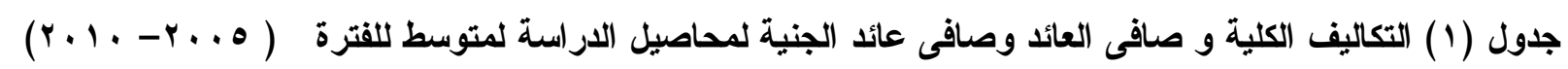

\begin{tabular}{|c|c|c|c|c|c|c|c|c|c|c|c|c|c|c|c|}
\hline \multicolumn{3}{|c|}{ الأرز صيفى } & \multicolumn{3}{|c|}{ ذرة شامية صيفى } & \multicolumn{3}{|c|}{ بصل شتوى } & \multicolumn{3}{|c|}{ برسيم مستديم } & \multicolumn{3}{|c|}{ القمح } & \multirow[t]{4}{*}{ السنو ات } \\
\hline صافى & صافى & إجمالى & صافى & صافى & إجمالى & صافى & صافى & إجمالى & صافى & صافى & إجمالى & صافى & صافى & إجمالى & \\
\hline عائد & العائد & التكاليف & عائد & العائد & التكاليف & عائد & العائد & التكاليف & عائد & العائد & التكاليف & عائد & العائد & التكاليف & \\
\hline الجنية & الفدان & الفدان & الجنية & الفدان & الفدان & الجنية & الفدان & الفدان & الجنية & الفدان & الفدان & الجنية & الفدان & الفدان & \\
\hline$\cdot, \wedge \wedge$ & $(r) \leqslant 9$ & $r \leq 00$ & $\cdot, \wedge 9$ & $|A r|$ & $r .00$ & $\cdot, \leqslant V$ & $\mid r \cdot \varepsilon$ & & $r, \cdot r$ & $r \leq T r$ & $11 \pi$. & $\cdot, \wedge \vee$ & אוגו & $r) \leqslant r$ & $r \ldots o$ \\
\hline$\cdot, \vee \vee 4$ & $r \cdot r$. & r701 & $\cdot, 10$ & $|\wedge N|$ & $r T \cdot T$ & $1, r_{1}$ & rra. & rVqu & $r, .0$ & Tr & 1194 & $\cdot, V Y$ & 1879 & $r \leq \varepsilon \varepsilon$ & $r \ldots r$ \\
\hline$\cdot, 99$ & r.r. & $r .70$ & 1,17 & $r .01$ & TTYE & $1, \wedge \vee$ & OrAV & rAYV & $r, \wedge 0$ & סזדמ & ITVT & $1,7 \varepsilon$ & 0109 & $M \leq 0$ & $r \ldots v$ \\
\hline.,$O \mathrm{~V}$ & rroq & rqז & r,or & ivor & rrqv & r & $71 \ldots$ & $r \cdot \varepsilon$. & $r, r \varepsilon$ & 07.1 & 1780 & זד, & Y) 9. & $r \leq 09$ & $r \ldots \lambda$ \\
\hline$\cdot, 70$ & $r \leq 0 \wedge$ & rVAᄉ & $\cdot, \leqslant 9$ & 1711 & r.r & $1,9 \varepsilon$ & 7тq. & rrq. & $r, r q$ & אדצד & سז19 & ס ז, & $19 \vee 0$ & rт人. & $r \ldots q$ \\
\hline$\cdot, \wedge \leq$ & $r \leq r$. & $\varepsilon \cdot V r$ & $\cdot, 70$ & $r \leq r$. & rvi. & $r, .0$ & $V \cdot 79$ & $r \leq r \wedge$ & $r, 10$ & $77 \cdot 1$ & $r .97$ & • ro & 1980 & rus. & $r \cdot 1$. \\
\hline$\cdot, \mathrm{V} \wedge$ & roo9,0 & r"Y, & $\cdot, V 7$ & $r .91, r$ & 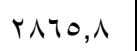 & 1,09 & $\leqslant 9.0$ & $r$ & $r, 1$ & $\sum \wedge \wedge 0$ & 100. & $\cdot, \vee \vee T$ & $r \leq \wedge \Lambda, 0$ & $r .91,1$ & متوسط \\
\hline
\end{tabular}

المصدر : جمعت وحسبت من وز ارة الزر اعة و الاستصلاح الأر اضى ، قطاع الثئون الاقتصادية ، نشرة الإقتصاد الزراعى ، أعداد متقرقة. 
جدول (Y) العمالة البشرية وإجمالى عدد الأيام اللازمة لزراعة فدان من المحاصيل موضع الدراسة

\begin{tabular}{|c|c|c|c|c|}
\hline إجمالى العمالة & ولد / يوم & إمر أة / يوم & رجل / يوم & المحاصيل \\
\hline$r \leq$ & $\varepsilon, r$ & $\cdot, \wedge$ & 19 & القمح \\
\hline$r \cdot, V$ & $0, V$ & $r, 0$ & $1 Y, 0$ & ذرة شامية صيفى \\
\hline$r 0, \Lambda$ & 7,0 & $\varepsilon, V$ & $1 \leqslant, 7$ & الأرز صيفى \\
\hline$r\rceil, \varepsilon$ & 7,1 & $r, \Lambda$ & 17,0 & برسيم مستذيم \\
\hline$\pi r, \varepsilon$ & IA, V & $\varepsilon$ & $\varepsilon \cdot, V$ & بصل شتوى \\
\hline
\end{tabular}

المصدر : جمعت وحسبت من وزارة الزر اعة و الاستصلاح الأر اضى ، ، قطاع الشئون

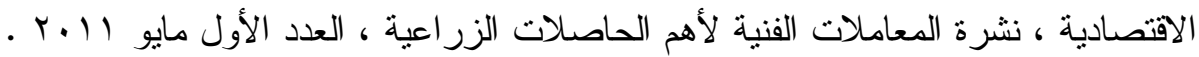

جدول (r) متوسط المساحة والإتتاج المحلى و المتاح للإستهلاك وصافى الغذاء و الفجوة الغذائية

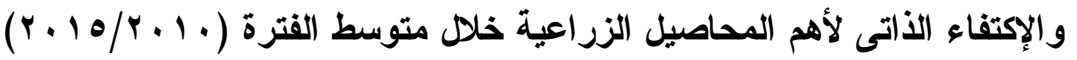

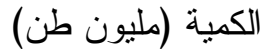

\begin{tabular}{|c|c|c|c|c|}
\hline 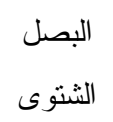 & الأرز & 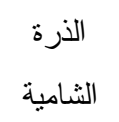 & القمح & البيان \\
\hline$r, \varepsilon$ & $r, v$ & $\vee, 7$ & $\wedge, \wedge$ & الإنتاج المحلى \\
\hline 1,9 & $0, r$ & $M, T$ & 17,9 & المتاح للإستههالك \\
\hline $1, \varepsilon$ & $\Gamma, \varepsilon$ & $0, \varepsilon$ & 11,0 & صافى الغذاء \\
\hline$\cdot, \wedge T$ & $\cdot, 9 \leq r$ & $0,0-$ & $0,77-$ & الفجوة الغذائية \\
\hline & $1.0,9$ & $r \cdot r$ & 01,1 & الإكتقاء الذاتى \\
\hline$\cdot, \ldots, r$ & $\begin{array}{c}\cdot, \cdot r \\
T\end{array}$ & .,. & זדי., & تدهور كل ( 1 من الإكتفاء الذاتى نتيجة فقد الف \\
\hline
\end{tabular}

المصدر:الجهاز المركزى للتعبئة العامة والإحصاء ، نثرة حركة الإنتاج والتجارة الخارجية والمتاح للإستهلالك لأهم

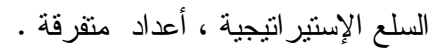




\section{جدول (؛) تطور الجدارة الإنتاجية لأهم محافظات الجمهورية خلال متوسط الفترة}

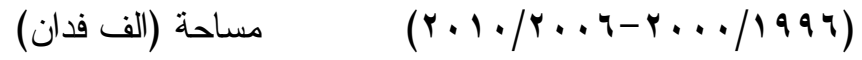

\begin{tabular}{|c|c|c|c|c|c|c|c|c|c|c|}
\hline \multicolumn{2}{|c|}{ القئة: الخامسة } & \multicolumn{2}{|c|}{ الفئة الر ابعة } & \multicolumn{2}{|c|}{ الفئة الثلألثة } & \multicolumn{2}{|c|}{ الفئة الثنانية } & \multicolumn{2}{|c|}{ الفئة الأولي } & \multirow[t]{3}{*}{ المدافظان } \\
\hline$-Y_{\ldots} . . Y$ & -1999 & $-r_{\ldots}$ & -1999 & $-r_{. .}$ & -1999 & $-T_{. .1}$ & -1999 & $-r_{\ldots} . .1$ & $r \ldots / 1999$ & \\
\hline r.1. & r... & r.1. & r... & r.1. & r... & r.1. & r... & Y.1. & & \\
\hline . & . & . & . & $r . \xi, Y$ & $r \mu, \varepsilon$ & or,A & mis & . & $1 \leqslant, 1$ & السكندرية \\
\hline . & . & $Y Y, Y$ & . & . & . & $r, 9, r$ & $\vdots \mu$ & $7 \times 9,0$ & $\$ 10,0$ & لبديرة: \\
\hline . & . & . & . & . & . & $1 \leqslant, Y$ & $101, Y$ & $r \leqslant 9,0$ & $r \leqslant \gamma, 0$ & الغربية \\
\hline . & . & . & . & . & $m, 1$ & $r \cdot 9, r$ & . & roy,o & $r \leqslant r, \Lambda$ & كفر الشُبخ \\
\hline ؛9 & . & . & . & . & . & $\mid r r, \Lambda$ & $\lambda i, 9$ & $\{00,1$ & $1 \leqslant Y$ & الدقهلية \\
\hline . & . & $1 \leqslant, 1$ & . & . & . & 97,1 & rrt,i & 09 & $r 0, r$ & دمياط \\
\hline . & . & $\Lambda \leqslant, 0$ & $1 A, Y$ & 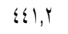 & . & $\llbracket \$$ & $o y, Y$ & $Y \xi, Y$ & $\{r 1,1$ & المُرَقِية \\
\hline . & . & $r Y, q$ & . & $\mid r r, 8$ & $1 \cdot r, 9$ & $\{\Lambda, Y$ & . & . & . & الأسماعبلية \\
\hline . & . & . & . & . & 0,9 & . & . & . & . & بورسعيد \\
\hline . & . & . & . & 1,0 & $r_{0,0}$ & . & . & $|A|, Y$ & . & السو يس \\
\hline . & . & . & . & . & . & $1 \leqslant r$ & MMA, & . & $\{0,\{$ & المنوفية \\
\hline $1 \%, \varepsilon$ & . & . & . & . & r. & $1 A_{\cdot, i}$ & $1 \leqslant 4, Y$ & . & $Y Y, \Lambda$ & القليوبية \\
\hline$r, Y$ & $\{, Y$ & . & . & $\{, Y$ & 1,0 & . & . & . & . & القاهزة: \\
\hline 10 & $\vdots, Y$ & 199,1 & $1 A, Y$ & VqY,O & $r \cdot 7, r$ & IVIr,i & 11001,0 & r..v & rert & اجمالى الوجه للبدرى \\
\hline$V Y, 9 Y$ & . & 179,1 & . & $r, r$ & . & 10,9 & 144,1 & $\mathrm{vr}$ & 00 & الجيزة \\
\hline . & . & , & . & . & $1 \leqslant 9,1$ & $M \xi \leqslant, 0$ & $11 \leqslant, \lambda$ & $r q, 99$ & . & بني سوريف \\
\hline . & . & $\Lambda_{1,1}$ & . & 7,1 & $19 \%, y$ & $r \cdot 1, r$ & $\mid \leqslant \Lambda,\{$ & 11,0 & . & القبرم \\
\hline . & . & . & . & . & . & $\mu \psi q, v$ & $17 \%, 1$ & $q Y, Y$ & $r v \leqslant, r$ & المنيا \\
\hline$V W, 97$ & . & $r_{0}, r^{\prime}$ & . & $A_{\cdot, Y}, Y$ & $r \leqslant \Psi, \Gamma$ & 917,6 & $04 r, 9$ & $r y 9,19$ & $r Y q, r$ & اجمالى هصر الوسطى \\
\hline . & . & . & . & . & . & T & $Y 10, Y$ & . & 99 & أسبوط \\
\hline . & . & . & . & . & . & 191,8 & $r 90,1$ & $1 . \xi, Y$ & . & سو هاج \\
\hline . & . & . & . & . & ro & $r \mu$ & IVI & $Y \cdot 0,9$ & 119,9 & قنا \\
\hline . & . & . & . & . & . & . & . & $1.1,9$ & . & الأصر \\
\hline . & . & 9,9 & . & $r\{\cdot, \lambda$ & $\{r, \xi$ & $q Y, Y$ & $1 \gamma, 9$ & $\{\Lambda$ & $1 \times r, 9$ & اسو ان \\
\hline . & . &, 9 & . & $Y \measuredangle \cdot, \lambda$ & $V Y, \xi$ & $\pi Y 4, Y$ & $v \cdot 0,1$ & 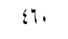 & $r \leqslant r, A$ & اجمالى مصر العليا \\
\hline . & $\{r o, Y$ & . & $110, r$ & $r \cdot 1,1$ & . & . & . & $r \Lambda, 1$ & . & الو ادي الجبليد \\
\hline$\{, y$ & . & $\lfloor १, Y$ & . & $\lambda, 0$ & . & . & . & . & . & مطروح \\
\hline$\cdot$ & . & . & . & $\therefore, y$ & . & . & . & . & . & البدر الآدمر \\
\hline 16,1 & $m M 1,0$ & $Y 1,1$ & . & . & . & . & . & . & . & شُمال سبناء \\
\hline . & . & 01,1 & $11, y$ & $1 \%, 1$ & . & . & . & . & . & جنوب سيناء \\
\hline . & . & . & . & 91 & Ir $\leqslant, 9$ & 0,0 & . & . & . & للنوباربة \\
\hline$Y \leqslant \Lambda, Y$ & $v, i, 0$ & $0 \times 9,0$ & Y10,1 & $1 \leqslant 17$ & $1 Y 01, A$ & $r \mu \cdot r, r$ & MaYt,r & TYYS & r... & اجمالي الجمهورية \\
\hline
\end{tabular}

المصدر جمعت وحسبت من وزارة الزر اعة والاستصلاح الأر اضى ، مركز البحوث الزر اعية ، معهد بحوث الاقتصاد

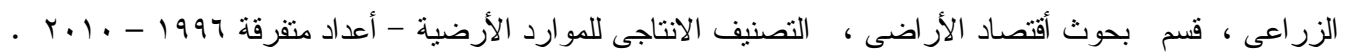

